\title{
Structural Definition and Mass Estimation \\ of \\ Lunar Surface Habitats \\ for the \\ Lunar Architecture Team Phase 2 (LAT-2) Study
}

\author{
John T. Dorsey, K. Chauncey Wu, Russ Smith \\ NASA Langley Research Center \\ John.T.Dorsey@nasa.gov,K.Chauncey.Wu@nasa.gov,_Russell.W.Smith@nasa.gov
}

\begin{abstract}
The Lunar Architecture Team Phase 2 study defined and assessed architecture options for a Lunar Outpost at the Moon's South Pole. The Habitation Focus Element Team was responsible for developing concepts for all of the Habitats and pressurized logistics modules particular to each of the architectures, and defined the shapes, volumes and internal layouts considering human factors, surface operations and safety requirements, as well as Lander mass and volume constraints. The Structures Subsystem Team developed structural concepts, sizing estimates and mass estimates for the primary Habitat structure.

In these studies, the primary structure was decomposed into a more detailed list of components to be sized to gain greater insight into concept mass contributors. Structural mass estimates were developed that captured the effect of major design parameters such as internal pressure load. Analytical and empirical equations were developed for each structural component identified. Over 20 different hard-shell, hybrid expandable and inflatable soft-shell Habitat and pressurized logistics module concepts were sized and compared to assess structural performance and efficiency during the study. Habitats were developed in three categories; Mini Habs that are removed from the Lander and placed on the Lunar surface, Monolithic habitats that remain on the Lander, and Habitats that are part of the Mobile Lander system.

Each category of Habitat resulted in structural concepts with advantages and disadvantages. The same modular shell components could be used for the Mini Hab concept, maximizing commonality and minimizing development costs. Larger Habitats had higher volumetric mass efficiency and floor area than smaller Habitats (whose mass was dominated by fixed items such as domes and frames). Hybrid and pure expandable Habitat structures were very mass-efficient, but the structures technology is less mature, and the ability to efficiently package and deploy internal subsystems remains an open issue.
\end{abstract}

\section{Symbols}

A

$\mathrm{A}_{\mathrm{s}}$

a

$\mathrm{C}_{\mathrm{i}}$

$\mathrm{D}$ area

area of truss strut

span between floor supports

empirical constant/coefficient for mass estimation equations

panel bending stiffness 


$\begin{array}{ll}\text { E } & \text { Elastic Modulus for an isotropic material } \\ \mathrm{E}_{\mathrm{xx}} & \text { Young's Modulus in x direction for composite truss struts } \\ \mathrm{F}_{\mathrm{xx}} & \text { open hole tension strength allowable } \\ \mathrm{f}(\alpha) & \text { empirical buckling coefficient } \\ \mathrm{g} & \text { gravity load (Earth normal value) } \\ \mathrm{H} & \text { height of dome } \\ \mathrm{h} & \text { thickness of honeycomb core } \\ \mathrm{I} & \text { area moment of inertia } \\ \mathrm{L} & \text { beam length for floor sizing } \\ \mathrm{l} & \text { column length for truss struts } \\ \mathrm{MT} & \text { Metric ton (1000kg) } \\ \mathrm{P} & \text { applied compressive load on truss struts } \\ \mathrm{p} & \text { pressure } \\ \mathrm{Q} & \text { line load for floor sizing } \\ \mathrm{q} & \text { distributed pressure load } \\ \mathrm{R} & \text { radius of dome } \\ \mathrm{R}_{\mathrm{S}} & \text { truss strut radius } \\ \mathrm{r} & \text { radius } \\ \mathrm{t} & \text { thickness of skins } \\ \mathrm{t}_{\mathrm{s}} & \text { thickness of truss strut wall } \\ \mathrm{W}_{\mathrm{c}} & \text { mass of the truss strut column } \\ \mathrm{W} & \text { flange width for floor beams } \\ \mathrm{w}_{\mathrm{f}} & \text { mid-span floor panel displacement } \\ \mathrm{W}_{\mathrm{L}} & \text { mid-span floor beam displacement } \\ \mathrm{x}, \mathrm{y}, \mathrm{Z} & \text { parametric input variables in mass formulations } \\ \alpha & \text { aspect ratio of dome (=H/R) } \\ \rho & \text { material density } \\ \sigma & \text { stress } \\ \sigma_{\mathrm{yiel}} & \text { stress, yield } \\ \sigma_{\mathrm{ult}} & \text { stress, ultimate } \\ v_{\mathrm{xy}} & \text { Poisson' ratio in the plane of quasi-isotropic composite } \\ v & \text { Poisson' ratio for an isotropic material } \\ & \\ & \end{array}$

\section{Introduction}

The recently completed Lunar Architecture Team Phase 2 (LAT-2) study defined and assessed six different architecture options for establishing and sustaining a Lunar Outpost at the moon's South Pole. The LAT-2 study was organized into a Campaign Team (CT), Architecture Option Teams (AOT) and a series of Focus Element Teams (FETs). The CT was responsible for developing the concept of operations and mission design for each of the different architectures, determining the order and timing for landing systems on the lunar surface, and estimating the logistics required to support long term outpost operations. A total of ten FETs, representing the major systems and technologies required to conduct the lunar outpost campaign, were also established to support the CT. The FETs were; In-Situ Resource Utilization, Launch Vehicle, Landers, Habitation, Surface Operations/Extra-Vehicular Activity, Surface Mobility, Power, Science, Communications/Navigation and Robotics. The FETs developed system concept 
definitions, operations concepts, preliminary sizing and mass data and cost inputs for the particular system implementations being considered by each of the architectures. Many design iterations occurred between the CT, Architecture Teams and FETs allowing the system concepts to evolve and be refined during the course of the study.

The Habitation Team was responsible for developing concepts for all of the permanent Habitats, sortie Habitats and pressurized logistics modules (PLMs) particular to each of the six architectures. Of those six architectures, the first four had a direct impact on Habitat concepts, while options 5 and 6 focused on introducing pressurized rovers early in the outpost delivery sequence, and using nuclear (instead of solar) power, respectively. For the first four architecture options, Habitats were developed in three categories; Habitats removed from the Lander and placed on the lunar surface (Mini Habs), Habitats that remained on the Lander permanently (Monolithic), and Habitats that were part of a mobile Lander system (Figure 1). The Habitation Team defined the shapes, volumes and internal layouts for each Habitat considering human factor requirements (long-term stay, crew of four), Lander mass and volume constraints, lunar surface operations requirements (attaching Habitat and logistics modules) and safety requirements (number of airlocks required for example). For each Habitat concept, a Master Equipment List (MEL) was developed that detailed the types, number, mass and power usage for each Habitat subsystem element. The major subsystems in the MEL were; structures, protection (micro-meteoroid and radiation), power management and distribution, thermal, avionics, life support, suit-lock/air-lock, and internal outfitting. Teams were established for each subsystem and were responsible for developing and providing all technical information for the MELs.

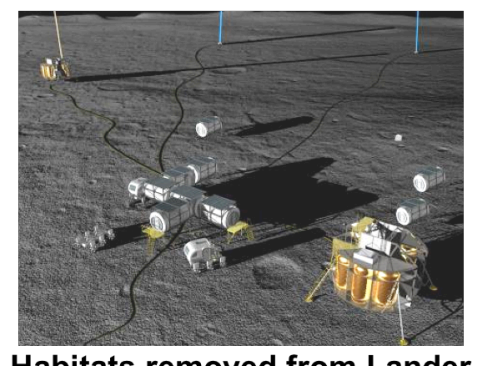

Habitats removed from Lander

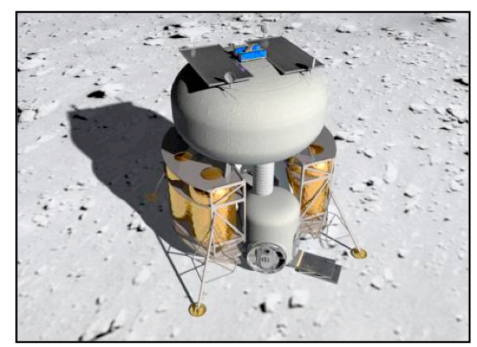

Habitat remains on Lander

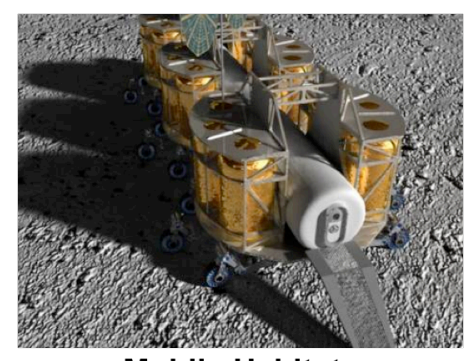

Mobile Habitats

Figure 1. Major Habitat categories considered in LAT-2.

The Structures Subsystem Team developed structures and materials concepts, sizing estimates and mass estimates for the primary Habitat structure, which consisted of the pressure shell, launch and Lander integration, and planetary surface support. A major objective for this study was to gain greater insight into structural mass (compared to parametric methods) by decomposing the primary structure into a more detailed list of components to be sized. A second objective was to ensure that mass estimates would capture trends resulting from changes in major design parameters, such as internal pressure load, factors-of-safety, dimensions, material type, etc. The final objective was to determine which factors had the largest impact on overall concept mass and determine if achieving mass reduction required technology development, more detailed design, increased fidelity in loads, refinement in assumptions, better knowledge of environments, and so on. 
This paper will summarize the different categories of Habitats considered for the various architectures and describe the methods developed and used to size and estimate the mass of the primary structural elements. The input data, such as material properties, factors of safety, loads and requirements, and minimum gage thicknesses will be described. Materials and structure options for hard-shell, soft-shell and hybrid (mixture of hard-shell and soft-shell components) Habitats will be described. Sizing results will be presented and options for the various architecture Habitats compared. Finally, observations and conclusions pertaining to Habitat structures, as well as recommendations for technology development, will be made.

\section{Habitat Definition and Mass Estimation}

\section{General Description}

The Habitat is an enclosed system that contains all of the hardware and systems necessary to sustain the life and ensure the safety of the crew. The Habitat System must protect the crew from all of the external lunar environments; radiation, temperature extremes, vacuum, dust and micrometeoroids. It should provide sufficient volume and space to satisfy crew physiological and psychological needs for long-term stay in a hostile environment. It also needs to provide means for egress/ingress and interfacing with other lunar surface system elements, such as pressurized rovers. These functions must also be within the context of the LAT-2 reference architectures, and resulting implementations depicted in Figure 1. Major architecture features, assumptions, constraints and options had to be considered as Habitat concepts were developed, with many being imposed by other systems, such as the Lander and Mobility FETs. A representative set of Habitat design drivers are summarized in Table 1.

\begin{tabular}{|c|c|c|}
\hline Driver & Type & Options/Specifications \\
\hline Mass & Constraint & $\begin{array}{l}\text { Multiple Habitats all < } 6 \text { MT; Single Delivery } 17-20 \\
\text { MT }\end{array}$ \\
\hline $\begin{array}{l}\text { Number of } \\
\text { Habitat elements } \\
\text { and interfaces }\end{array}$ & Trade & $\begin{array}{l}\text { Number of separate Habitat volumes required, number of } \\
\text { interfaces required for each Habitat, types of operations } \\
\text { required to assemble Habitats }\end{array}$ \\
\hline Consumables & Trade & Resupply for 4 crew at 180 -day intervals; $<6 \mathrm{MT}$ \\
\hline $\begin{array}{l}\text { Habitable } \\
\text { Volume }\end{array}$ & Trade & $\begin{array}{l}\text { Total volume required, habitable volume required, } \\
\text { degree of personal/private space, resulting Habitat shapes } \\
\text { and dimensions }\end{array}$ \\
\hline $\begin{array}{l}\text { Environmental } \\
\text { Control and Life } \\
\text { Support }\end{array}$ & Trade & Degree of system closure; partial, moderate, complete \\
\hline Emplacement & Trade & Remain on Lander, offloaded from Lander \\
\hline Mobility & Trade & $\begin{array}{l}\text { Built into Habitat element, built into Lander element, } \\
\text { accommodated by surface mobility element }\end{array}$ \\
\hline $\begin{array}{l}\text { Radiation } \\
\text { Protection }\end{array}$ & Trade & $\begin{array}{l}\text { Built into Habitat, provided by In-situ resources. } \\
\text { Protection against Solar Particle Events only, or add } \\
\text { protection for Galactic Cosmic Rays. }\end{array}$ \\
\hline
\end{tabular}

Table1. Habitat Major Design Drivers. 
To varying degrees of fidelity, the Habitat team developed over 20 different concept definitions that could be applied to the three major implementations shown in Figure 1. These concepts usually implemented different specifications within the trade options listed in Table 1 and were presented to the Architecture Option leads, who made the final decision on which option to baseline for their campaign analyses. The total Habitat System mass and power was accumulated in a MEL spreadsheet for each sized Habitat. Each subsystem team was responsible for defining the detailed list of items that would appear in their section of the MEL, and then providing the accompanying concept definitions, mass and power estimates. Because of the large number of options considered, and the rapid pace at which the study progressed, each Habitat subsystem team was limited in the fidelity of concept definition, analysis, sizing and mass estimation that could be applied to each of their subsystems. A general goal was to increase fidelity beyond applying gross parametric methods at the subsystem level, but recognizing that the realm of design (even conceptual) could not be entered given the nature of the LAT-2 study.

Both major and minor elements were selected for structural sizing. Although both sets of elements were common across all concepts investigated, details of the minor elements varied from one concept to the next. The major structural elements such as the pressure shell, ground support, launch and Lander integration, floor system, secondary structure and miscellaneous were based upon, respectively, the induced pressure loads, the mass of the envisioned Habitat, the structure required to interface with both the launch vehicle and the Lander, a distributed pressure load for Earth outfitting and check out as well as additional supports for floor sections, internal bulkheads, and so on. Both the major and minor elements were chosen for sizing due to their critical nature as load-bearing structure for the Habitat outpost. The generic major and minor elements are listed in Table 2 below.

\begin{tabular}{|l|l|}
\hline \multicolumn{1}{|c|}{ Major Structural Elements } & \multicolumn{1}{c|}{ Minor Elements/Details } \\
\hline Pressure Shell & \\
\hline & Forward Dome \\
\hline & Forward Dome-to-Barrel Frame \\
\hline & Barrel \\
\hline & Barrel-to-Aft Dome Frame \\
\hline Legs/Ground Support System & Aft Dome \\
\hline Launch \& Lander Integration Structure & Barrel Frames \\
\hline Floor System & \\
\hline & \\
\hline & Floor Beams \\
\hline & Floor Panels \\
\hline Secondary (Internal) Support Structure & Floor Edge Supports \\
\hline Miscellaneous & \\
\hline Structural Non-Optimums & \\
\hline
\end{tabular}

Table 2. Structural Elements for Lunar Habitat Sizing. 


\section{Mass Estimation Philosophy, Options and Approach}

A general hierarchy of options available for estimating the mass and sizing of structural elements, as well as a description of these methods, is summarized in Table 3. In general, as one moves down the approaches listed in the Table, the level of fidelity of the analysis, insight into the results and confidence in the results will increase. However, at the same time, additional knowledge is required with respect to loads and environments, design requirements, subsystem design details, material properties and failure modes, to complete an analysis. In general, two distinct levels of approach exist for estimating structural mass and sizing, with the distinction being whether or not any element design is performed, as indicated by the demarcation (given by the bold line) in Table 3.

\begin{tabular}{|c|c|c|c|}
\hline Approach & Description/Example of Method & $\begin{array}{c}\text { Mass } \\
\text { Estimation? }\end{array}$ & $\begin{array}{l}\text { Structural } \\
\text { Sizing? }\end{array}$ \\
\hline Allocation & $\begin{array}{l}\text { A percentage of some overall vehicle measure, } \\
\text { such as gross mass: } \\
\text { Landing System }=2.8 \% \text { Landed Mass (Apollo) }\end{array}$ & Yes & No \\
\hline $\begin{array}{l}\text { Parametric: } \\
\text { Single Input } \\
\text { Variable, } \mathrm{x}\end{array}$ & $\begin{array}{l}\text { Curve fit of historical data gives coefficients: } \\
\text { e.g., } \mathrm{y}=\mathrm{C}_{\mathrm{o}}+\mathrm{x}^{\mathrm{C}} \\
\text { (where } \mathrm{x}=\text { vehicle gross mass, wetted area, etc.) } \\
\text { (wos }\end{array}$ & Yes & No \\
\hline $\begin{array}{l}\text { Parametric: } \\
\text { Multiple } \\
\text { Input } \\
\text { Variables }\end{array}$ & $\begin{array}{c}\mathrm{Y}=\mathrm{Co} * \mathrm{x} * \mathrm{y} * \mathrm{z} \\
(\text { where } \mathrm{x}=\text { dimension, } \mathrm{y}=\text { pressure, } \mathrm{z}=\text { etc. })\end{array}$ & Yes & No \\
\hline $\begin{array}{c}\text { Simple } \\
\text { Analytical }\end{array}$ & $\begin{array}{c}\mathrm{t}=(\mathrm{P} * \mathrm{R}) /\left(2 * \sigma_{\mathrm{ult}}\right) \\
\text { Plus: Additions/factors for Non-Optimum mass }\end{array}$ & Yes & Yes \\
\hline $\begin{array}{l}\text { Design- } \\
\text { Based } \\
\text { Analysis }\end{array}$ & $\begin{array}{l}\text { Conceptual Design } \\
\text { Preliminary Design } \\
\text { Detailed Design }\end{array}$ & $\overline{\text { Yes }}$ & Yes \\
\hline
\end{tabular}

Table 3. Hierarchy of Mass Estimation and Sizing Techniques.

As is typical in architecture level studies, the typical information needed for design, such as detailed structural requirements, loads, environments, and system interfaces, was not available for the Habitats in the LAT-2 study. Additionally, a large number of concepts needed to be defined and evaluated in a short period of time using only limited resources. As a result, only concept definitions could be developed for each of the primary structure subsystem items listed in Table 2, and only methods above the bold line in Table 3 were considered.

In many previous architecture studies, Habitat masses were estimated using the parametric/single input variable method and relied extensively on equations and data from Heineman, (1994). This report is intended to be used primarily for conceptual efforts, such as architecture studies, where time and detailed information are not normally available to allow for rigorous design and analysis efforts. The equations in this reference take on the form of row 2 in Table 3, with asbuilt hardware mass data (spanning spacecraft from Mercury to the Space Shuttle) used to generate the coefficients in the equations. Categories for manned spacecraft and space station 
mass estimates include vehicle gross mass, vehicle body structure mass and propellant fuel (launch) vehicle system mass. The report states that variations of $\pm 35 \%$ are reasonable for first level estimating, substantiated by the fact that some mass estimates for previous vehicles have grown by more than $50 \%$ from concept to operation, despite the benefit of considerable efforts in design and analysis. Limitations of this method include: 1) the data represents predominantly aluminum alloy materials and structures, which would imply the same for any forecasts; 2) there is a large amount of scatter in the data (off of the fitted curves); and, 3) the method provides no insight into differences that might result from changes in load conditions, requirements, system lifetime, structural concepts, and materials choices.

Major goals for the Habitat Focus Element Team were to help the Architecture Teams differentiate between the different Habitat implementations (shown in Figure 1), and help the LAT-2 study identify potential high-payoff technologies that should be considered for development. To meet these goals, greater insight was required for the Habitat primary structure subsystem. The first step into achieving this insight was to increase the fidelity of the structural subsystem by identifying its major elements (see Table 2). In the approach adopted for structural mass estimation and structural sizing, a mix of analytical and empirical equations were developed and applied to each of these elements. The second step was to capture changes in mass and sizing resulting from changes in major design parameters, such as; pressure, geometry, dimensions (such as Habitat radius or length), factor-of-safety, material type and material design values, in the appropriate equations.

The method from Table 3 that was applied to each of the structural elements listed in Table 2 was based on available mass data, Heineman (1994), element complexity and the level of concept definition, definition of interfaces to other systems (especially the Lander), and number of different geometries considered. The methods chosen are summarized in Table 4.

\begin{tabular}{|l|l|l|}
\hline \multicolumn{1}{|c|}{ Major Element } & \multicolumn{1}{|c|}{ Structural Concept } & \multicolumn{1}{c|}{ Mass Estimation Method } \\
\hline SHELL & & Simple Analytical \\
\hline Domes and Barrel & Sandwich & Parametric \\
\hline Internal Frames & NA & Allocation (2.6\% of gross mass) \\
\hline INTERNAL \& INTEGRATION & & Simple Analytical \\
\hline Legs/Ground Support System & NA & $\begin{array}{l}\text { Allocation (based on surface } \\
\text { area) }\end{array}$ \\
\hline Floor System & Sandwich & Allocation (2.0\% of gross mass) \\
\hline Internal Support Structure & NA & Simple Analytical \\
\hline Launch and Lander Integration & NA & $\begin{array}{l}\text { Allocation (25.0\% of structural } \\
\text { mass) }\end{array}$ \\
\hline $\begin{array}{l}\text { External Support Structure } \\
\text { (Mini-Habs and PLM) }\end{array}$ & Truss & NA \\
\hline $\begin{array}{l}\text { Non-Optimum/Unsized } \\
\text { Structure }\end{array}$ & & \\
\hline
\end{tabular}

Table 4. Mass Estimation Methods for Habitat Structural Elements.

Two decisions were made at the outset of the effort; the first was to improve the fidelity of the mass estimates while allowing for rapid concept sizing, and the second was to improve the 
validity of the final estimate. In the first case, a sandwich structure was chosen for the shell, with frames only at the dome-to-barrel intersections. Unlike a stiffened shell, where the axial and bending strength and stiffness depend on the frame and stringer structural arrangement, sandwich structures inherently obtain bending stiffness from the core separating the facesheets. Thus, it is a simple matter to size the sandwich skins to resist membrane loads, estimate a core thickness, and perform checks to determine if adequate margins exist for bending stresses and buckling. In this case, the sandwich concept is used to estimate mass, and no inference is made as to whether or not the sandwich concept is preferred over a stiffened skin concept. The validity of this approach is borne out by the fact that optimized stiffened skin shells have been sized which have a mass that is very close to that of sandwich shells for certain stiffener/frame combinations (see Table $2 \mathrm{~b}$ in Shiedeler et al (1972)). When minimum gage is considered, it has also been shown that optimized stiffened skin and sandwich shells have very nearly identical mass when lightly loaded (see Figure 15 in Agarawal et al, (1977)).

In the second case, the lack of design detail led to many structural subelements not being included in the mass estimate, resulting in an estimate that was overly optimistic. The general approach when estimating structural mass is to include a category, usually called "NonOptimums" for structure that is either not represented or is un-sized. Examples of such details include weld lands, splice plates, joints, fittings, high-density core, pad-up regions around cutouts, shims, etc. The amount of mass allocated to these Non-Optimums is a function of the degree of detailed design that has been performed. In this case, the structures team chose to allocate and add $25 \%$ of the final sized mass to obtain the final structural mass that was forwarded for the MEL. At the Habitat system level, the campaign team specified that a mass factor of $20 \%$ be applied to all systems (to reflect the general level of uncertainty at this level of study), and was added to obtain the final Habitat System mass.

\section{Element Mass Estimation - Structural Sizing Equations Development}

\section{Cylindrical barrels}

This section presents results on the development of structural sizing equations for lunar Habitat components. Many of the Habitats evaluated in this study are comprised of hard-shell, right circular cylinders (barrels) with ellipsoidal end closures (domes). The predominant loading imposed on these configurations is internal pressure. The thickness of a thin-walled cylinder under internal pressure is determined by the circumferential stress by Beer and Johnson (1981). The uniform wall thickness, $t$, of this cylinder is given as

$$
\mathrm{t}=(\mathrm{p} * \mathrm{FS} * \mathrm{R}) / \sigma
$$

where $\mathrm{p}$ is the nominal internal pressure, FS is a factor of safety, $\mathrm{R}$ is the cylinder radius, and $\sigma$ is the material allowable stress. These definitions are also used throughout the remainder of this section.

Other proposed concepts for lunar Habitats use inflatable cylindrical barrel sections to provide high packaging efficiency with large deployed volumes. A representative concept for an inflatable Habitat is presented in a report by Stein et al. (1997). The flexible wall of this Habitat 
is comprised of several layers. The innermost layer is an abrasion-resistant lining, which is covered with a single pressure bladder that contains the Habitat atmosphere. The outer loadbearing layer is comprised of uniformly spaced, biaxial Kevlar webbing sewn to a fabric base. Twice as many straps are oriented in the circumferential direction as in the axial direction to account for the higher circumferential loads. The areal mass ( $\rho t)$ of an inflatable cylinder can be estimated as

$$
\rho \mathrm{t}=\mathrm{C}_{0}+\mathrm{C}_{1} * \mathrm{p} * \mathrm{FS} * \mathrm{R}
$$

where $\mathrm{C}_{0}$ and $\mathrm{C}_{1}$ are empirical constants. Based on data from Stein et al. (1997), $\mathrm{C}_{0}=0.513$ $\mathrm{kg} / \mathrm{m}^{2}$, and $\mathrm{C}_{1}=1.754 \times 10^{-6} \mathrm{~s}^{2} / \mathrm{m}^{2}$. If additional pressure bladders are desired for redundancy, $\mathrm{C}_{0}$ should be increased by $0.308 \mathrm{~kg} / \mathrm{m}^{2}$ per additional bladder. To ensure dimensional consistency, the pressure must be given in Pascal's (i.e. $\mathrm{N} / \mathrm{m}^{2}$ ) and the ring frame radius in meters, for a resulting areal mass in kilograms per square meter.

\section{Ellipsoidal domes}

Typical barrel end domes are comprised of elliptical hemispheroidal shells. The aspect ratio $(\alpha)$ of an elliptical dome is defined as $\mathrm{H} / \mathrm{R}$, where the apex height is $\mathrm{H}$ and the base radius is $\mathrm{R}$. Sizing of this ellipsoidal configuration is based on the uniform biaxial stress state at the apex of the dome. The uniform wall thickness, determined using data from Baker, et al. (1968), is computed as

$$
\mathrm{t}=(\mathrm{p} * \mathrm{FS} * \mathrm{R}) /\left(2 * \sigma^{*} \alpha\right)
$$

The wall thickness of a thin hemispherical dome under internal pressure, computed by setting $\alpha$ to 1 in Equation 3, is equal to one-half of the thickness computed using Equation 1.

To increase Habitat packaging efficiency on the Lander, it may also be desirable to make the dome apex height as low as possible. Under internal pressure, the circumferential stresses at the dome equator can be compressive for an ellipsoidal dome with an aspect ratio less than 0.707 Thurston and Holston (1966). Therefore, buckling is a failure mode that must be considered when sizing these shallower designs. NASA SP-8032 (1969) gives the following equation for sizing the uniform wall thickness of ellipsoidal domes with aspect ratios between 0.25 and 0.60 to resist buckling,

$$
\mathrm{t}=\left[\left\{\mathrm{p} * \mathrm{FS} * \mathrm{R}^{2} *\left(3-3 * v^{2}\right)^{0.5}\right\} /\{2 * \mathrm{E} * \mathrm{f}(\alpha)\}\right]^{0.5}
$$

In Equation 4, E and $v$ are the dome material elastic modulus and Poisson's ratio (respectively). Also, $f(\alpha)$ is an empirical coefficient which is plotted over a range of aspect ratios in Figure 2 for an $R / t$ of 1000. Note that the material allowable stress $\sigma$ does not appear in Equation 4, since buckling is explicitly a stiffness-driven phenomenon. 


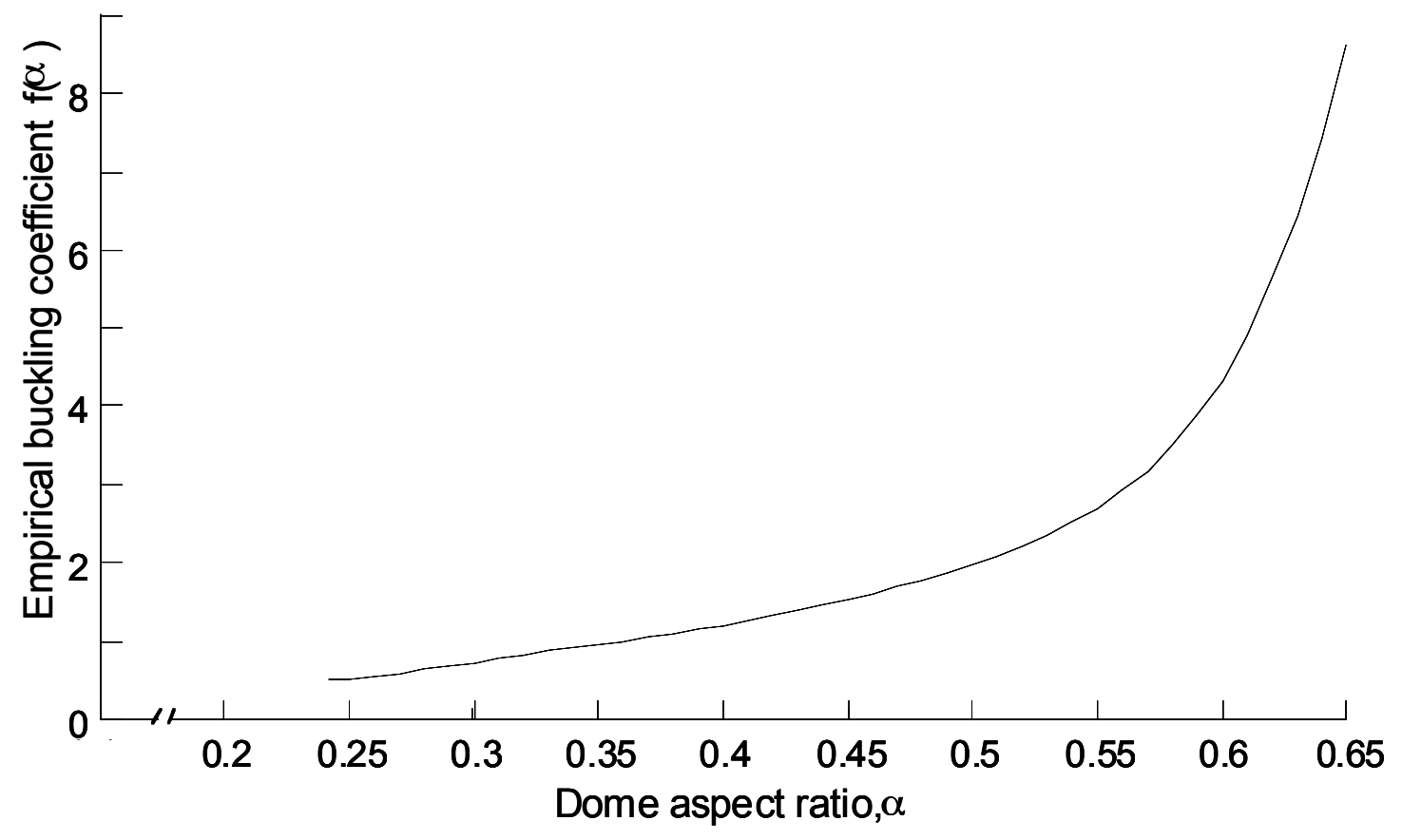

Figure 2. Empirical buckling coefficient $f(\alpha)$ vs. aspect ratio $(\alpha)$.

Habitat end domes may also be made from inflatable softgoods only if their aspect ratio is greater than 0.707 to eliminate wrinkling as a failure mode. A sizing equation for an inflatable dome concept that is similar to the inflatable cylindrical barrel described above is developed using data from Stein et al. (1997), where

$$
\rho t=C_{0}+C_{2} * p * F S * R / \alpha
$$

and $\mathrm{C}_{0}$ and $\mathrm{C}_{2}$ are empirical constants. As computed for Equation $2, \mathrm{C}_{0}=0.513 \mathrm{~kg} / \mathrm{m}^{2}$. However, $\mathrm{C}_{2}=1.169 \times 10^{-6} \mathrm{~s}^{2} / \mathrm{m}^{2}$, or $2 / 3$ of the value of $\mathrm{C}_{1}$. This relationship between $\mathrm{C}_{1}$ and $\mathrm{C}_{2}$ arises because the highest normalized stresses (located at the dome apex) are both equal to the normalized axial stress in a cylindrical shell of the same diameter (which is then equal to onehalf of the normalized circumferential stress).

\section{Ring frames}

In this study, all major ring frames at dome-to-cylinder interfaces are made from composite materials. An assumed sizing relationship for circular ring frames is developed with the functional form

$$
\mathrm{M}_{\text {ring }}=\mathrm{C}_{3} * \mathrm{p} * \mathrm{FS} * \mathrm{R}
$$


where $\mathrm{C}_{3}$ is an empirical constant. The mass of a ring frame developed for an inflatable Habitat concept (Stein et al. (1997)) is used to determine an empirical value of $\mathrm{C}_{3}=1.798 \times 10^{-4} \mathrm{~s}^{2}$. If a metallic ring frame mass is desired, then the relationship in Equation 6 can be multiplied by the ratio of metallic and composite material densities.

\section{Floors}

The Habitat floors are honeycomb sandwich panels with minimum-gage face sheets made from the same material as the Habitat shell wall. These floor panels are 0.889 meters wide, with simply supported edges. A dead load of 7182 Pascals (in a 1g field) with a 1.5 factor of safety is used to represent the loads applied during testing and outfitting on Earth. The honeycomb core thickness is chosen to limit the panel center deflection to one percent of the 0.889 -meter span under this loading. Timoshenko and Woinowsky-Krieger (1987) give an equation for the center deflection of a semi-infinite plate under a distributed load, which is

$$
\mathrm{w}_{\mathrm{f}}=0.01302 * \mathrm{q}^{*} \mathrm{a}^{4} / \mathrm{D}
$$

In Equation 7, $\mathrm{q}$ is the distributed load, a is the span between simple supports, and D is the panel bending stiffness. Substitution of $0.01 * a$ for $\mathrm{w}_{\mathrm{f}}$ and solution for the bending stiffness gives

$$
\mathrm{D}=1.302 * \mathrm{q}^{*} \mathrm{a}^{3}
$$

The approximate bending stiffness of a honeycomb sandwich plate is (Vinson, 1999)

$$
\mathrm{D}_{\mathrm{hc}}=\mathrm{E}^{*} \mathrm{t} * \mathrm{~h}^{2} /\left\{2 *\left(1-\mathrm{v}^{2}\right)\right\}
$$

where $\mathrm{t}$ is the face sheet thickness, and $\mathrm{h}$ is the honeycomb core thickness. After setting Equations 8 and 9 equal to each other, and then solving for the core thickness,

$$
\mathrm{h}=1.614 *\left[\left\{\mathrm{q}^{*} \mathrm{a}^{3} *\left(1-\mathrm{v}^{2}\right)\right\} /(\mathrm{E} * \mathrm{t})\right]^{0.5}
$$

This is the minimum honeycomb core thickness required to limit the floor panel center deflection to $1 \%$ of the 0.889 meter free span.

\section{Floor beams}

The floor support structures for the vertically-integrated Habitats with large open floor areas are assumed to be simply supported wide flange I-beams. The applied loading is based upon the same dead load of $7182 \mathrm{~N} / \mathrm{m}^{2}$ distributed over the entire floor surface and multiplied by a 1.5 factor of safety. The entire floor is broken up into 0.889 meter-wide floor panel sections that are then centered over a supporting floor beam. This results in a beam line load value equal to 9579 $\mathrm{N} / \mathrm{m}$. 
The beam center deflection is assumed to be one percent of its length. Using an equation from Beer and Johnson (1981) for a simply supported beam under a distributed load, this center deflection is

$$
\mathrm{w}_{\mathrm{L}}=0.01302 * \mathrm{Q} * \mathrm{~L} / \mathrm{EI},
$$

where $\mathrm{Q}$ is the line load, $\mathrm{L}$ is the beam length, and EI is the beam bending stiffness. Substitution of $0.01 * \mathrm{~L}$ for $\mathrm{w}_{\mathrm{L}}$ and solution for the beam moment of inertia gives

$$
\mathrm{I}=1.302 * \mathrm{Q}^{*} \mathrm{~L}^{3} / \mathrm{E}
$$

Neglecting higher-order terms in $t$, the approximate equation for the beam moment of inertia is

$$
\mathrm{I}=\left(\mathrm{t}^{*} \mathrm{~h}^{3}\right) / 12+2 * \mathrm{w}^{*} \mathrm{t} *(\mathrm{~h} / 2)^{2}
$$

where $t$ is the section thickness, $h$ is the web height and $w$ is the flange width. The beams are assumed to have a web height that is 80 times the section thickness and a flange width that is 40 times the section thickness. Thus, the section thickness becomes the only sizing variable. Substituting the assumed web height and flange width into Equation 13, the floor beam inertia is

$$
I=170,670 * t^{4}
$$

Substituting Equation 14 into Equation 12 and solving for $\mathrm{t}$ yields

$$
\mathrm{t}=\left[7.63 \times 10^{-6} * \mathrm{Q}^{*} \mathrm{~L}^{3} / \mathrm{E}\right]^{0.25}
$$

The central floor beams for the smaller horizontally integrated Habitats were made from the same honeycomb sandwich construction used for the floor panels. Each floor beam was assumed to have a $\mathrm{C}$-cross section with a web height equal to the perpendicular distance between the floor centerline and the Habitat shell wall.

\section{Floor edge supports}

The floor systems for the vertical Habitats are supported on ring frames attached to the cylindrical sections. If the floor location coincides with an existing ring frame, the existing ring frame is then assumed to support the floor. The sizing relationship for circular ring frames developed in Equation 6 is used to compute the floor edge support mass at locations where no ring frame exists. For the smaller horizontal Habitats, the floor edge supports are assumed to have a mass equal to one-half of the $\mathrm{C}$-section central floor beam.

\section{Legs/ground support system}

The mass required for Habitat legs and ground support systems is highly concept-dependent. Therefore a simple estimate is made by defining this mass to be a percentage of the Habitat gross 
mass. Data from Heinemann (1994) indicates that the Apollo Lunar Module landing gear (220 $\mathrm{kg}$ ) supports a vehicle landed mass of $7909 \mathrm{~kg}$. Division of these two values gives a value of 2.78 percent for the Apollo Lunar Module legs and ground support systems. Application of modern design methods and structural materials should allow some reduction of this empirical coefficient, which is assumed to be equal to 2.60 percent of the Habitat gross mass for this study. Therefore,

$$
\mathrm{M}_{\mathrm{LGSS}}=0.026 *(\text { Habitat gross mass })
$$

\section{Launch and Lander integration structure}

As noted for the legs and ground support systems, Habitat launch and Lander integration structures are also concept-dependent. Under study options 3 and 4, these Habitats are assumed to remain on the Lander. For the purposes of this study, the Habitat launch and Lander integration structure mass is assumed to be equal to 2 percent of the Habitat gross mass.

$$
\mathrm{M}_{\text {LLIS }}=0.020 *(\text { Habitat gross mass })
$$

\section{Secondary (internal) support structure}

Secondary structures are required to support various subsystems inside the Habitat during outfitting, launch and lunar operations, with the mass, volume and location of these subsystems ill-defined at this stage of Habitat conceptual definition. The mass of the internal reinforcement to the Habitat sandwich shell structure necessary to attach these secondary structures is represented by an empirical coefficient multiplied by the Habitat shell surface area.

$$
\mathrm{M}_{\text {SISS }}=\left(2.46 \mathrm{~kg} / \mathrm{m}^{2}\right) *(\text { Habitat shell surface area })
$$

\section{Cargo-Truss Struts}

An external cargo truss structure is assembled to the exterior of the Mini-Habs and serves to integrate the Habitat with the Lander. It provides an interface for handling and transportation loads experienced on the lunar surface. The truss struts are assumed to be hollow tubes and have a circular cross-section. The tubes are sized for a compression load, P, taking into account Euler Buckling, local wall buckling and strength using the method in Appendix A of Mikulus et al. (1977). The structural index form for a minimum mass column is given by,

$$
\mathrm{W}_{\mathrm{c}} / 1^{3}=\left(4 / \mathrm{c}^{*} \mathrm{c}_{1} * \pi\right)^{1 / 3}\left(\rho_{\mathrm{c}} / \mathrm{E}^{2 / 3}\right)\left(\mathrm{P} / \mathrm{l}^{2}\right)^{2 / 3}
$$

Mikulus et al. (1977) uses a value of 0.9 for the constant c, and 0.36 for the constant $\mathrm{c}_{1}$, which are also used in this study. The truss struts assumed are high-stiffness aluminum-clad graphite epoxy, as described in Ring (1990). The high structural efficiency of these struts is obtained from the uni-directional high-modulus graphite epoxy forming the central layer of the strut. A thin layer of aluminum cladding, that provides crush and handling strength, damage tolerance, dimensional stability and protection from radiation, forms both the interior and exterior layers of 
the strut. Equation 19 provides the mass per unit length of the graphite epoxy layer. In order to calculate the tube mass, the geometry must be determined. If equation 19 is multiplied by $1^{2}$, its results can be substituted into

$$
\mathrm{A}_{\mathrm{s}}=\mathrm{W}_{\mathrm{c}} /(1 * \rho)
$$

to obtain $A_{s}$, the total cross-sectional area of the strut. For a thin-walled strut, the relationship between the strut radius, $R_{s}$, and it's wall thickness $t_{s}$ is given by

$$
\mathrm{R}_{\mathrm{s}} * \mathrm{t}_{\mathrm{s}}=\mathrm{A}_{\mathrm{s}} /(2 * \pi)
$$

The mass of the aluminum cladding can be calculated using

$$
\mathrm{W}_{\mathrm{Al}} / 1=\rho_{\mathrm{Al}} * 2 *\left(2 * \pi * \mathrm{R}_{\mathrm{s}} * \mathrm{t}_{\mathrm{Al}}\right)
$$

The total mass per unit length of the strut is the sum of equation 19 multiplied by the column length squared, plus equation 22 .

\section{Input Data}

This section summarizes the input data that was used for sizing and estimating masses of the Habitat structural elements. The data includes material properties, loads, factors of safety and minimum gage values.

\section{Material Properties}

Both metallic and polymeric composite (PMC) materials were considered for the Habitat primary structure. The materials are subjected to long term exposure to the extreme environments present on the lunar surface, including various forms of radiation, vacuum and extreme temperatures. Ideally, material properties would be established for end-of-life (could assume 15 years exposure for example), and those properties used for design with load cases included for various temperature conditions. In addition, because of the long lifetime expected for the structures, and possible exposure to damage (including micrometeoroids), appropriate material properties and damage scenarios would also be included in the design. In most cases, the material information needed for potential applications to a lunar surface Habitat do not exist, and the nature of the architecture study only allows for simple assessments. The approach for this study was to obtain, or assume, the equivalent of statistically based material strength allowables that represent beginning-of-life values, and use room temperature properties. These assumptions are not conservative, especially for polymeric composite materials.

For the metallic material, an aluminum lithium (Al-Li) alloy is assumed, with properties that are representative of the alloy used in the Space Transportation System External Tank (Al-Li 2195T8). The strength values represent an S-basis allowable for thin plate, and are summarized in Table 5. The polymeric composite material assumed is based on a bismalimide (BMI) resin with an intermediate modulus fiber, IM7/5250-4. Because of the limited number of load cases, large uncertainty in environments, lack of information on required damage tolerance, etc., quasi- 
isotropic, notched (open hole compression) properties were used for the BMI. In addition, only typical values for the material properties are contained in reference High Speed Research Program (1998), so the design allowable is obtained by using 85 percent of the typical value (references High Speed Research Program (1998) and Niu (1992)). The resulting material properties are summarized in Table 5.

\begin{tabular}{|l|l|l|}
\hline Property & $\begin{array}{l}\text { Al-Li 2195-T8 } \\
\text { (Representative) }\end{array}$ & $\begin{array}{l}\text { IM7-5250-4 } \\
\text { Quasi-Isotropic }\end{array}$ \\
\hline Density $\left(\mathrm{kg} / \mathrm{m}^{3}\right)$ & 2700. & 1580. \\
\hline $\mathrm{E}_{\mathrm{T}}, \mathrm{Al}-\mathrm{Li} / \mathrm{E}_{\mathrm{XX}}, \mathrm{PMC}($ tension modulus, $\mathrm{MPa})$ & $73,800$. & $56,900$. \\
\hline$\sigma_{\mathrm{ult}}, \mathrm{MPa}-$ allowable & 538. & NA \\
\hline$\sigma_{\text {yield }} \mathrm{MPa}-$ allowable & 503. & NA \\
\hline Fxx, oht, $\mathrm{MPa}-$ baseline, typical & $\mathrm{NA}$ & 494. \\
\hline Fxx, oht, $\mathrm{MPa}-$ allowable $(85 \%$ of baseline) & $\mathrm{NA}$ & 420. \\
\hline$v / v_{\mathrm{xy}}$ & 0.33 & 0.30 \\
\hline
\end{tabular}

Table 5. Material Property Data (Room Temperature).

As noted previously, the cylindrical shell walls, the domes, the floors and the floor beams are all assumed to be sandwich structures to allow for analytical mass estimates. The properties for the aluminum honeycomb core, adhesive, the strut aluminum cladding/graphite epoxy all derive from High Speed Research Program (1998) and are summarized in Table 6.

\begin{tabular}{|l|l|l|}
\hline Item & Property 1 & Property 2 \\
\hline $\begin{array}{l}\text { Honeycomb Core } \\
(\text { Aluminum })\end{array}$ & Cell Size $=0.48 \mathrm{~cm}$ & Density $=80 \mathrm{~kg} / \mathrm{m}^{3}$ \\
\hline Adhesive - Film $($ FM X5) & Thickness $=0.036 \mathrm{~cm}($ avg.) & Areal Density $=0.49 \mathrm{~kg} / \mathrm{m}^{2}$ \\
\hline Al cladding - truss struts & Thickness $=0.015 \mathrm{~cm}$ & Density $=2,700 \mathrm{~kg} / \mathrm{m}^{3}$ \\
\hline Graphite epoxy - truss struts & $\mathrm{E}_{\mathrm{xx}}=152,000 \mathrm{MPa}$ & Density $=1,580 \mathrm{~kg} / \mathrm{m}^{3}$ \\
\hline
\end{tabular}

Table 6. Miscellaneous Properties.

\section{Loads and Factors of Safety}

The Habitat internal operating pressure was the single load case used to size the pressure shell (barrel and domes). In addition, the axial launch load factor, in combination with the Habitat gross mass, was used to generate distributed line loads for modules oriented horizontally, as well as axially. These line loads were applied to the Mini-Hab based PLM module to check margins of safety for strength and buckling. For floor sizing, a uniform pressure was assumed, along with a deflection constraint of 1 percent of a representative span. For items that used the gross mass of the Habitat for mass estimates, $1 \mathrm{~g}$ acceleration was applied to obtain forces. Factors of safety were also applied to operating loads to obtain design ultimate loads used for analysis. The loads and factors of safety used in this study are summarized in Table 7. 


\begin{tabular}{|l|l|}
\hline Load & Magnitude \\
\hline Internal Pressure & $55,158 \mathrm{~N} / \mathrm{m}^{2}$ \\
\hline Launch load, axial factor & $3.86 \mathrm{~g}$ \\
\hline Floor Loading & $7180 \mathrm{~N} / \mathrm{m}^{2}$ \\
\hline Load Type & Factor of Safety \\
\hline Mechanical (metallic, PMC) & 1.5 \\
\hline Internal Pressure (metallic, PMC) & 2.0 (Pressure loading alone) \\
\hline Mechanical (Webbing, expandables) & 4.0 \\
\hline Internal Pressure (webbing, expandables) & 4.0 \\
\hline Buckling & 2.0 \\
\hline
\end{tabular}

Table 7. Loads and Factors of Safety.

\section{Minimum Gage}

Minimum gage is the minimum allowable thickness of material that can be used in a particular structural application. Minimum gage values are established based on a wide variety of considerations, including material (ductile metal, brittle metal, polymeric composite), structural concept (sandwich, stiffened skin, integrally stiffened), application (primary or secondary structure), design service life, potential damage scenarios, ability to inspect for critical damage, manufacturing considerations, handling considerations, and others. Minimum gage sets the lower limit for mass on lightly loaded structures. For studies that have very few load cases (such as architecture studies), minimum gage structure can typically be the result. Generally in design, as load cases are added, the amount of minimum gage structure is greatly reduced or eliminated. For the current study, the values of minimum gage were obtained from High Speed Research Program (1996) and correlate to primary structure with a 20-year lifetime that meet durability and damage tolerance requirements for commercial transports. The minimum gage for polymeric composite materials assumes a standard ply thickness of $0.0127 \mathrm{~cm}$ and standard laminate design rules that result in durable and damage tolerant structure, Niu (1992). The rules that are especially important are those for balanced and symmetric laminates, and placing \pm 45 degree plies on the outer surface of the laminate to increase damage tolerance. The values used in this study are summarized in Table 8 .

\begin{tabular}{|l|l|l|}
\hline Material & $\begin{array}{l}\text { Sandwich Application: } \\
\text { thickness, cm }\end{array}$ & $\begin{array}{l}\text { Skin/Laminate Application: } \\
\text { thickness, cm }\end{array}$ \\
\hline $\begin{array}{l}\text { Aluminum/Aluminum } \\
\text { Lithium }\end{array}$ & $0.051^{*}$ & 0.102 \\
\hline $\begin{array}{l}\text { Polymeric Composite (quasi- } \\
\text { isotropic) }\end{array}$ & $0.140(10-$ ply)* & 0.203 \\
\hline Aluminum Honeycomb Core & 1.270 & NA \\
\hline
\end{tabular}

*Per facesheet in sandwich structure.

Table 8. Primary Structure Minimum Gage. 


\section{Habitat Analysis Results}

Structural sizing and mass estimating was performed for Habitats associated with the three architecture options shown in Figure 1. Within Options 2 (Mini-Habs) and 3 (Monolithic) Habitats, a variety of implementations were assessed and presented to the architecture team. This section summarizes the various concept definitions and associated analysis results.

\section{Option 2 - Mini Habitats}

An objective of Option 2 was to be able to include a Habitat module on a crewed flight. From the initial estimates of Lander payload capacity, the goal for the Habitat team became to limit the gross mass of a preintegrated, pressurized Habitat module to a maximum of 6 MTs. The Option 2 architecture also baselined that the Habitat modules would be off-loaded from the Lander and emplaced on the lunar surface to form the outpost. Thus, the Mini-Habs also had to incorporate means for ground payload handling and transport on the lunar surface, ground support and leveling, and connection between adjacent modules. The reference outpost concept, shown on the left in Figure 3, consisted of 5 Mini-Hab modules resulting in a total volume of $137 \mathrm{~m}^{3}$, and supported; extravehicular operations and maintenance, internal crew operations and sleep area, mission operations, galley and wardroom, medical operations and science laboratory, exercise, and logistics stowage-pantry. The configuration shown also has a PLM attached, and allows two pressurized rovers to be mated with the outpost.
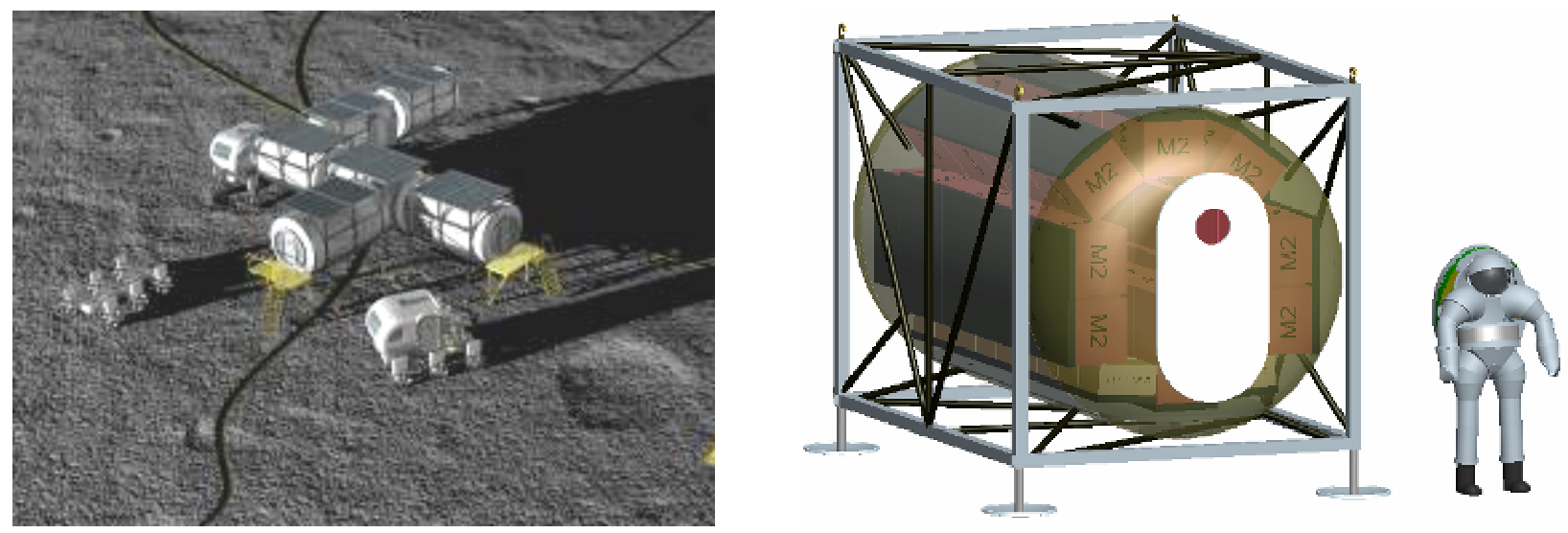

Figure 3. Mini-habs in outpost configuration and PLM.

A hybrid hard-shell/mid-expandable concept was also developed and evaluated. The complete outpost using hybrids would consist of 3 mid-expandable Habitats for a total volume of $189 \mathrm{~m}^{3}$ as shown in Figure 4. The mid-expandables are landed on the lunar surface as pre-integrated unpressurized units that, once emplaced, are subsequently expanded and outfitted. The subsystems are pre-integrated into the hard shell assemblies to simplify ground processing and simplify deployment on the surface. 

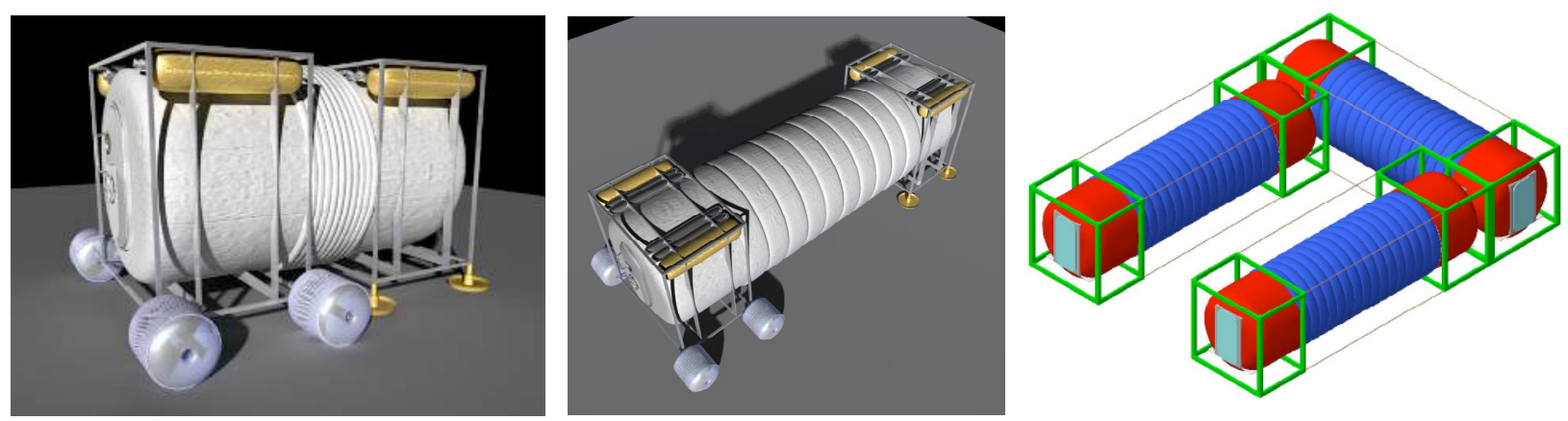

Figure 4. Hybrid expandable mini-hab and outpost configuration.

The nominal interior dimensions of a Mini-Hab module were 2.75 meters in diameter by 5 meters in length, resulting in a pressurized volume of approximately $27.5 \mathrm{~m}^{3}$ for each module. The end domes have an aspect ratio of $0.53(.715 / 1.35)$ resulting in a dome height of 0.715 meters and a barrel length of 3.57 meters. Because the Mini-Habs were to be off-loaded from the Lander and placed on the lunar surface, an external cargo handling truss (as shown on the PLM, right side of Figure 3) was integrated to the exterior of the module. This truss had several functions, including; integrating the module with the Lander, transferring launch loads from the Mini-Hab into the Lander, serving as the cargo handling structure on the lunar surface, and serving as the structure to which the ground support legs and leveling system would be attached. Exterior systems, such as solar arrays and radiator panels, or panels that could support regolith and provide long-term protection from galactic cosmic radiation, could also be added. The MiniHab module is supported in the interior of the cargo truss with struts connecting the corners of the cargo truss to the exterior of the module at the dome-to-barrel-to-frame interface. The truss has a 3-meter square cross section in the plane of the end dome (see Figure 3) and has two 2.5 meter long bays along the length of the module. The truss struts are assumed to be circular crosssection aluminum-clad graphite epoxy, as described previously. A pressurized logistics module (PLM) is used to transport logistics to the lunar outpost. Structurally, the PLM is identical to an Al-Li Mini-Hab but has a slightly higher assumed gross mass (5200 kg for the PLM versus 5123 $\mathrm{kg}$ for the Mini-Hab), smaller floor, and only has a door/hatch cutout in one dome.

For the hard-shell Mini-Habs and PLM, the pressure shell is a sandwich structure, and both Aluminum-Lithium and Polymeric Composite skins were evaluated. The material assumed for the pressure shell is also assumed for the floor structure. The material properties, loads, and factors of safety cited previously were used to size the structure. When sized for internal pressure, the sandwich walls of the domes and barrel resulted in minimum-gage structure for both materials (both facesheet and core thicknesses). The mass results for metallic and polymeric composite hard shell Mini-Habs are contained in Table 9. The mid-expandable concept is a hybrid that has both hard shell and soft shell components. The hard shell components consist of two dome, dome-to-barrel frame, and 1.29 meter barrel section assemblies. These attach to each end of a mid-expandable section that is 1 meter long when collapsed and 6 meters long when expanded, giving a total expanded length of 10 meters. The expandable section is assumed to have a single bladder. 


\begin{tabular}{|c|c|c|c|c|c|c|}
\hline \multirow{3}{*}{ Structural Item } & \multicolumn{6}{|c|}{ Mass, kg } \\
\hline & \multicolumn{2}{|c|}{ Al-Li } & \multicolumn{2}{|c|}{$\begin{array}{c}\text { PMC } \\
5.0 \mathrm{~m} \mathrm{~L}\end{array}$} & \multicolumn{2}{|c|}{$\begin{array}{c}\text { Mid- } \\
\text { Expandable } \\
\mathbf{1 0 . 0} \mathbf{~ m ~ L ~}\end{array}$} \\
\hline & $5.0 \mathrm{~m} \mathrm{~L}$ & $6.0 \mathrm{~m} \mathrm{~L}$ & $\begin{array}{l}\text { Base- } \\
\text { line }\end{array}$ & $\begin{array}{c}\text { Reduce } \\
\text { Min } \\
\text { gage }\end{array}$ & Al-Li & PMC \\
\hline 1.0 Pressure shell & 263 & 305 & 338 & 298 & 276 & 336 \\
\hline 1.1 Forward dome & 31 & 31 & 42 & 36 & 31 & 42 \\
\hline 1.2 Fwd. dome-to-barrel frame & 27 & 27 & 27 & 27 & 27 & 27 \\
\hline 1.3 Barrel & 143 & 185 & 194 & 167 & 156 & 191 \\
\hline 1.3.1 Hard shell & 143 & 185 & 194 & 167 & 103 & 139 \\
\hline 1.3.2 Expandable & NA & NA & NA & NA & 53 & 53 \\
\hline 1.4 Barrel-to-aft dome frame & 27 & 27 & 27 & 27 & 27 & 27 \\
\hline $1.5 \mathrm{Aft}$ dome & 35 & 35 & 48 & 41 & 35 & 48 \\
\hline 2.0 Legs/ground support system & 133 & 133 & 133 & 133 & 133 & 133 \\
\hline 3.0 Launch/lander integration & NA & NA & NA & NA & NA & NA \\
\hline 4.0 Floor system & 72 & 86 & 86 & 69 & 181 & 215 \\
\hline 4.1 Floor beams & 12 & 14 & 14 & 11 & 30 & 36 \\
\hline 4.2 Floor panels & 49 & 58 & 58 & 47 & 122 & 145 \\
\hline 4.3 Edge supports & 12 & 14 & 14 & 11 & 30 & 36 \\
\hline 5.0 Secondary structure support & 114 & 136 & 114 & 114 & 87 & 87 \\
\hline $\begin{array}{l}\text { 6.0 Miscellaneous: External } \\
\text { cargo truss }\end{array}$ & 62 & 66 & 62 & 62 & 69 & 69 \\
\hline Subtotal & 644 & 726 & 733 & 676 & 746 & 840 \\
\hline 7.0 Structural non-optimum & 161 & 182 & 183 & 169 & 187 & 210 \\
\hline Total Structure & 805 & 908 & 916 & 845 & 933 & 1050 \\
\hline
\end{tabular}

Table 9. Mini-hab Structural Mass Summary.

Since the gross mass of a Mini-Hab is limited by the Lander performance, a common gross mass of $5123 \mathrm{~kg}$ was assumed for all configurations evaluated. This led to the mass of the Legs/ground support system being identical. Since the Mini-Habs had an external cargo truss, the mass for launch/Lander integration structure is reported as zero. The launch acceleration and Habitat gross mass are used to calculate the loads in the cargo truss struts and size the struts. Thus, the truss mass is identical for modules with the same length. The truss mass for the mid-expandable concept, although 5 meters long when packaged, is slightly higher because two batten frames are needed at the center of the two bays to form two complete single truss bays, allowing for separation of the two hardshell ends after expansion of the midsection. The mass of the secondary support structure for the mid-expandable is slightly less than that for the other 5-meter long Al-Li modules because the hard shell portion of the barrel section is 1 meter shorter, and the areal mass factor is only applied to hard-shell structure. The aft dome in all cases is slightly heavier (than the forward dome) because its door cutout (circular with 0.914 meter diameter) has a smaller area than the hatch cutout (rectangular at $0.864 \times 1.829$ meters) and less material would be removed from the shell. For all of the Mini-Habs, the height of the floor is 0.33 meters above the shell wall, giving a floor width of 1.78 meters $(0.2$ and 1.42 meters respectively for the 
PLM), with the length of the floor the total length (expanded when appropriate) of the module. A central floor beam support runs along the length of the floor, giving a reference dimension of 0.89 meters for calculating stiffness using equation 8 . The floor panels and supports are assumed to be sandwich structure. Major features of the Mini-Hab definitions are summarized in Table 10 .

\begin{tabular}{|l|c|c|c|}
\hline Parameter, units & Hard-shell, 5.0 meter & Hard-shell, 6.0 meter & $\begin{array}{c}\text { Mid-expandable, } \\
\mathbf{1 0 . 0} \text { meter }\end{array}$ \\
\hline $\begin{array}{l}\text { Dimensions } \\
\text { (expanded), meters }\end{array}$ & $\begin{array}{c}2.7 \text { Diameter } \mathrm{x} \\
5.0 \text { Long }\end{array}$ & $\begin{array}{c}2.7 \text { Diameter } \mathrm{x} \\
6.0 \text { Long }\end{array}$ & $\begin{array}{c}2.7 \text { Diameter } \mathrm{x} \\
10.0 \text { Long }\end{array}$ \\
\hline Volume, $\mathrm{m}^{3}$ & 27.5 & 33.2 & 63.0 \\
\hline Surface area, $\mathrm{m}^{2}$ & 46.5 & 55.0 & 88.9 \\
\hline Floor area, $\mathrm{m}^{2}$ & 8.90 & 10.67 & 17.79 \\
\hline Floor height, meters & 0.33 & 0.33 & 0.33 \\
\hline Floor width, meters & 1.78 & 1.78 & 1.78 \\
\hline
\end{tabular}

Table 10. Mini-hab Definition Summary (per module).

A major result of the sizing analysis was that the pressure shell structures sized to minimum gage for both aluminum lithium and polymeric composite materials. This result may be attributed to the limited number of load cases and design definition noted previously, and could possibly change when Habitats are actually designed. In order to assess the validity of this result, the PLM (Al-Li sandwich) was chosen for additional analysis. In particular, Margin of Safety calculations were performed for stress and buckling for the PLM barrel in both a horizontal and a vertical orientation and for the PLM floor. For the barrel, the axial launch acceleration of the Ares V launch vehicle (see Table 7) together with the PLM gross mass and factor of safety was used to calculate an applied load with simply support boundary conditions assumed. For the vertical orientation, a uniform line load was calculated and applied as a compressive load to the circumferential perimeter of the barrel. For the horizontal orientation, a uniform line load was applied along the span of the barrel. Since the amount of payload that might be mounted to the floor (as opposed to mounted to the interior walls) during launch has not been defined, the static floor loading given in Table 7 was assumed. This would translate to a total floor load of $4155 \mathrm{~kg}$ at $1 \mathrm{~g}$, or to $1076 \mathrm{~kg}$ at a launch load acceleration of $3.86 \mathrm{~g}$. The resulting margins-of-safety for these various conditions are summarized in Table 11. Since the margins of safety were positive and very large for this application, checks were not performed on the other configurations. 


\begin{tabular}{|l|c|c|c|}
\hline \multicolumn{1}{|c|}{ Item/Orientation } & Applied Loading & $\begin{array}{c}\text { Condition Checked } \\
\text { (sandwich face sheet) }\end{array}$ & $\begin{array}{c}\text { Margin of } \\
\text { Safety }\end{array}$ \\
\hline Barrel/NA & Internal pressure & Strength & $266 \%$ \\
\hline Barrel/Vertical & Axial inertia & Strength & $6800 \%$ \\
\hline Barrel/Vertical & Axial inertia & Longitudinal buckling & $1288 \%$ \\
\hline Barrel/Horizontal & Transverse inertia & Strength & $3150 \%$ \\
\hline Barrel/ Horizontal & Transverse inertia & $\begin{array}{c}\text { Upper cross-section } \\
\text { buckling }\end{array}$ & $3083 \%$ \\
\hline Floor/Horizontal & Transverse inertia & $\begin{array}{c}\text { Strength, Sandwich face } \\
\text { sheets }\end{array}$ & $529 \%$ \\
\hline
\end{tabular}

Table 11. PLM Margins-of-Safety for Launch Load Conditions.

A direct result of the pressure shell sizing being minimum gage was that the aluminum lithium structure mass was lighter than polymeric composite structure (see Table 8 for minimum gage values). Although these values reflect a high degree of structural safety and damage tolerance (based on commercial transport aircraft), damage scenarios particular to lunar surface applications, as well as associated damage tolerance requirements must be established in order to obtain better estimates of structural mass. An example was calculated, where the minimum gage facesheet for polymeric composite was reduced from 10 to 8 plies (the resulting laminate that minimally satisfies requirements for a balanced, symmetric and quasi-isotropic layup), and is shown in Table 9. This resulted in reductions in the pressure shell and floor masses, and a reduction of approximately 8 percent in the total composite Mini-Hab mass. This is approximately 5 percent higher than the aluminum lithium structure mass, and should be considered essentially equivalent at the level of fidelity for this study. Given equivalent mass, a polymeric composite shell has significant advantages over a metallic shell with respect to radiation protection (which was not considered in this study).

\section{Option 3 - Monolithic Habitats}

The monolithic Habitation concepts established the Lunar Outpost using a single delivery by the Cargo version of the Lunar Lander, utilizing the entire Lander mass budget for the lunar outpost (a maximum nominal range of 17-20 metric tons). Also, the monolithic Habitats were sized to fit within the initial payload shroud of the Ares V launch vehicle (shroud diameter of 8.4 meters and a cylindrical height of approximately 18 meters). The monolithic concepts are denoted by simple letter designations: Monolithic-A, Monolithic-B, Monolithic-C and Monolithic-D. Common to all of the Monolithic Habitat structures is the utilization of Al-Li-2195-T8 for both the pressure shell sections and the honeycomb sandwich panel floor sections. Additionally, all of the floor support beams are assumed to be comprised of "I" beams which have a web section that is 80 times the flange thickness and a flange width which is 40 times the flange thickness. Floor sizing also assumes the distributed pressure load given in Table 7.

The Monolithic-A Concept geometry is shown if Figure 5 and consists of a total volume of $230 \mathrm{~m}^{3}$, a mid plane diameter of 7.5 meters and an overall height of 7.6 meters. Both the upper and lower ellipsoidal domes of the Habitat have an aspect ratio of 0.7071 with a dome height of 2.65 meters. The center barrel section has a diameter of 7.5 meters and a cylindrical height of 
2.14 meters. In general, this concept had the least amount of concept definition of all the concepts in this report.

There are a total of three floors with a spacing of 2.14 meters between each. The floors also utilize Al-Li 2195-T8 facesheets over a $2.54 \mathrm{~cm}$ honeycomb core as used for the pressure shell sections. The floor beam support spacing is 0.889 meters and a maximum mid span displacement criterion of $1 \%$ is applied to the allowable deflections of the floor section between supports. Three ring frame systems for floor support are also included. Internal pressure, as well as the pressure and mechanical loads factors of safety are as previously outlined.

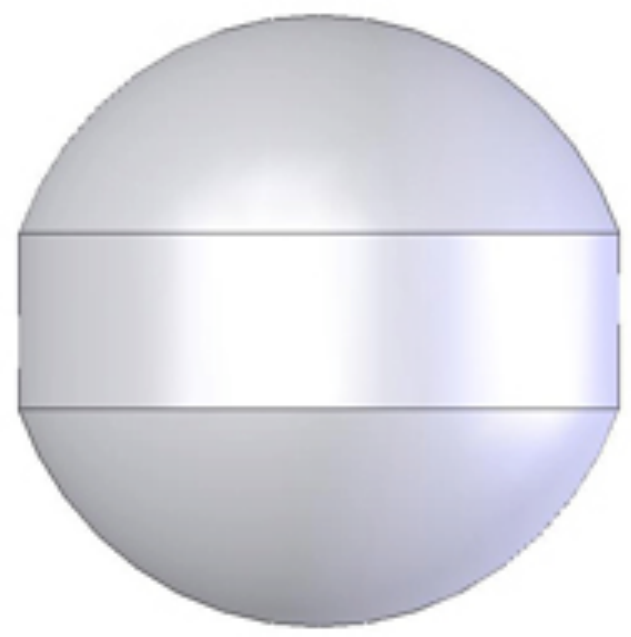

Figure 5. Monolithic concept A geometry.

The Monolithic-B Concept is shown in Figure 6. This concept consists of four floors; the first and second floors are contained within a cylindrical section, the third floor resides within a conic section and the fourth (and uppermost) floor is housed within a dome section. The total volume is $327 \mathrm{~m}^{3}$, with a major diameter of 7.5 meters and an overall height of 10.43 meters. The lower dome section (beneath the first floor) has an ellipsoid aspect ratio of 0.458 , a major diameter of 7.5 meters and a height of 1.72 meters. The center barrel section has a diameter of 7.5 meters and a total height of 4.28 meters. The conic section associated with the third floor has a major diameter of 7.5 meters, a height of 2.22 meters, and a ceiling diameter of 6.25 meters. The fourth and uppermost floor of the Habitat has a root diameter of 6.25 meters (equal to the ceiling diameter of the floor beneath it) and a height of 2.21 meters. As in the case for Concept A, Concept B also utilizes the aforementioned Al-Li 2195-T8 material system for the pressure shell and the floor panel sections. The floors are sandwich and are sized as outlined previously. There is one additional ring frame added for floor support purposes (as differentiated from the structural ring frames between shell segments). The leg support system assumptions and calculations are the same as outlined for the Monolithic-A concept but since no gross mass value was available a volumetric factor of 1.42 was applied (i.e., volume of Monolithic-B/volume of Monolithic-A $=1.42$ ) to the total Habitat mass of Concept A. 

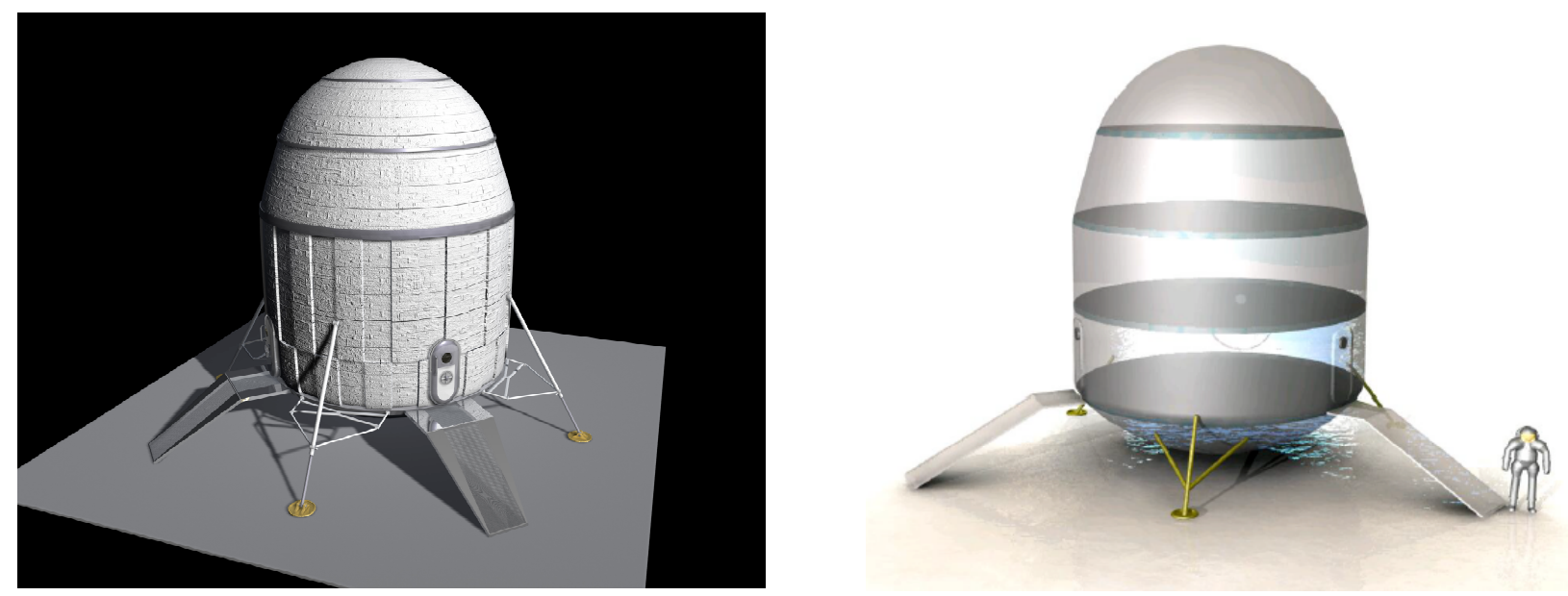

Figure 6. Monolithic concept B geometry.

The Monolithic-C Concept with its two "Drop Locks" (i.e. Airlocks) can be seen in Figure 7. This concept is an all ellipsoid dome Habitat with both the forward and aft domes having aspect ratios of 0.46 . The mid-line intersection point of the domes has a diameter of 7.5 meters. There is a single floor section which is positioned within the lower dome volume. Both domes have a height of 1.72 meters and the overall Habitat height equals 3.44 meters. The mass calculated for the legs and ground support system is that required for the legs and leveling system for the "Drop Locks" alone (since the concept assumes a fixed mounting to the Lunar Lander). The launch and Lander integration structure assumes a gross mass of 10 metric tons for sizing purposes. There are two access points for the Habitat through the two Drop-Locks shown in Figure 7. The DropTube portions of the Drop Locks have both rigid and flexible sections as well as a tube interface section which allows for the mating of the rigid and flexible parts (for a total of four ring sections within the Drop-Tubes).

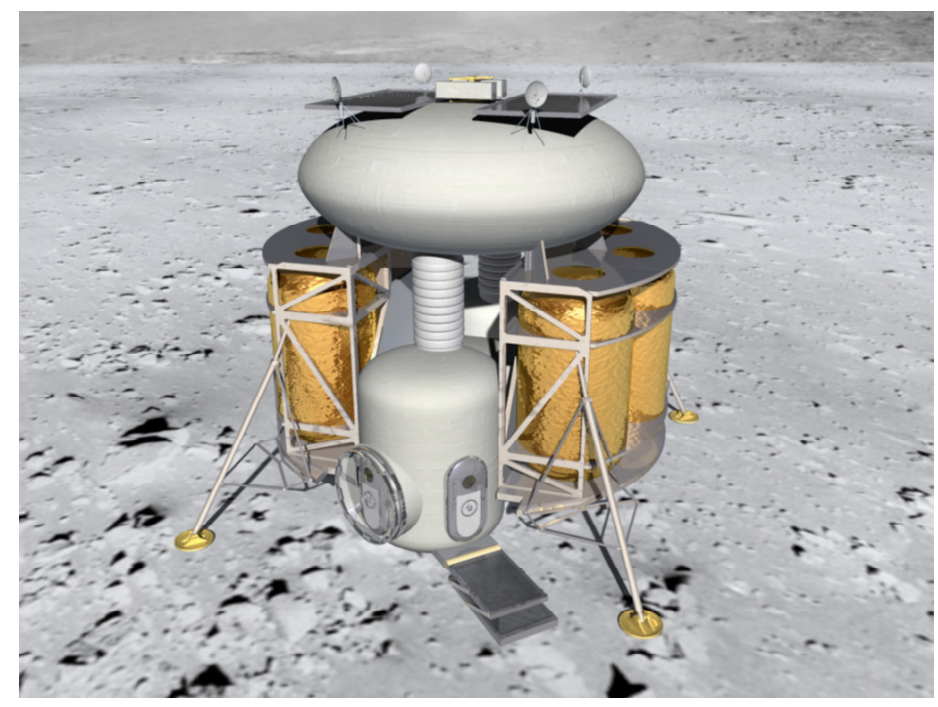

Figure 7. Monolithic concept C on Lander with Drop Lock. 
The Monolithic-D Concept with Drop Locks is shown in Figure 8 and is essentially Concept $\mathrm{C}$ with an added center barrel volume, as well as a lower sleeping compartment which is imbedded in the lower dome area. The domes and Drop-Locks are the same as for the Concept $\mathrm{C}$. The center barrel section is 1 meter high with a diameter of 7.5 meters, giving a total Habitat height of 4.45 meters. Again, as was the case for the Monolithic-C concept mass calculations for the legs and ground support system are based upon the legs and leveling system for the drop locks alone (i.e. permanently mounted to the Lunar Lander). For the launch and Lander integration structure an assumed gross mass of 12 metric tons is used. Floor mass calculations include an additional area based upon the sleeping quarters for the crew.

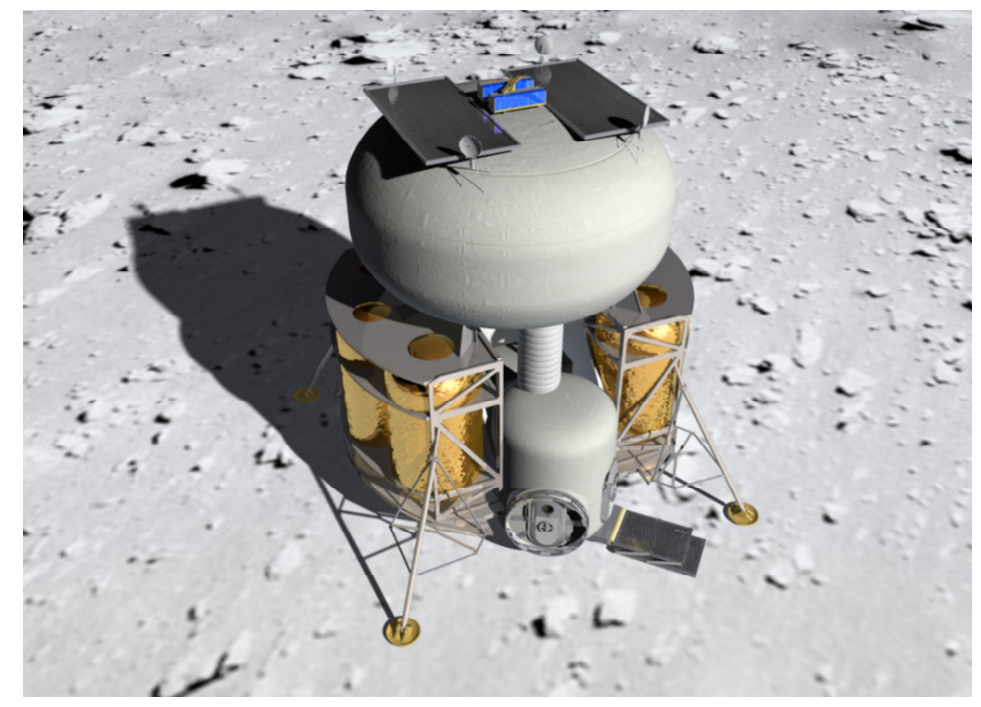

Figure 8. Monolithic concept D on Lander with Drop Lock.

As the later monolithic concepts (C and D) were being developed, the safety of having a single habitable pressurized volume was raised. For safety, there was a desire to partition the internal volume into two spaces using a pressure bulkhead. This bulkhead was defined to be vertical (perpendicular to the floor), flat, and divide the volume exactly in half. For mass efficiency the bulkhead was assumed to be a sandwich structure, using the same material as is used in the Habitat shell. The mass of the bulkhead was estimated with the same equations used to size the sandwich floor (equations 7 thru 10). The resulting bulkhead geometry used for analysis was that of a rectangular panel. The floor is assumed to break the panel span in the vertical direction, with the floor and the dome providing simple support conditions along the long edge. For Concept D, the resulting panel was 2.5 meters tall $\times 7.5$ meters long, and for Concept $\mathrm{C}$, the dimensions were 1.72 meters $\mathrm{x} 7.5$ meters. The panel is sized to support the internal design pressure while minimizing deflection in either direction. In order to mitigate core crushing, the maximum allowable core thickness was assumed to be $7.0 \mathrm{~cm}$ and in order to minimize mass, the constraint for the panel was relaxed such that a deflection of 5 percent of span was allowed. For integration with the shell, a frame was assumed along the perimeter of the bulkhead, using the same lineal mass as derived for the dome-to-barrel frames for each concept. The resulting bulkhead areas were $27.8 \mathrm{~m}^{2}$ for Concept $\mathrm{D}$ and $20.3 \mathrm{~m}^{2}$ for Concept C. Table 12 shows the itemized mass statements for all of the Monolithic concepts considered. 


\begin{tabular}{|c|c|c|c|c|}
\hline \multirow{2}{*}{ Structural Items } & \multicolumn{4}{|c|}{ Mass, $\mathbf{~ g}$} \\
\cline { 2 - 5 } & A & B & C & D \\
\hline 1.0 Pressure shell & 1265 & 1713 & 755 & 966 \\
\hline 1.1 Forward dome & 414 & 288 & 340 & 340 \\
\hline 1.2 Fwd. dome-to-barrel frame & 75 & 62 & 75 & 75 \\
\hline 1.3 Barrel & 287 & 947 & NA & 136 \\
\hline 1.3.1 Cylindrical shell & 287 & 585 & NA & 136 \\
\hline 1.3.2 Conical shell & NA & 287 & NA & NA \\
\hline 1.3.3 Mid frame & NA & 75 & NA & NA \\
\hline 1.4 Barrel-to-aft dome frame & 75 & 75 & NA & 75 \\
\hline 1.5 Aft dome & 414 & 341 & 340 & 340 \\
\hline 2.0 Legs/ground support system & 439 & 623 & 130 & 130 \\
\hline 3.0 Launch/Lander integration & 337 & 479 & 200 & 240 \\
\hline 4.0 Floor system & 1798 & 2245 & 347 & 617 \\
\hline 4.1 Floor beams & 932 & 1278 & 163 & 356 \\
\hline 4.2 Floor panels & 653 & 892 & 129 & 261 \\
\hline 4.2.1 Main deck(s) & 653 & 892 & 129 & 242 \\
\hline 4.2.2 Sleep area & NA & NA & NA & 19 \\
\hline 4.3 Edge supports & 213 & 75 & 55 & NA \\
\hline 5.0 Secondary structure support & 246 & 470 & 291 & 350 \\
\hline 6.0 Miscellaneous & NA & NA & 548 & 729 \\
\hline 6.1 Drop Lock Tunnels & NA & NA & 106 & 136 \\
\hline 6.1.1 Drop tubes (rigid section) & NA & NA & 59 & 89 \\
\hline 6.1.2 Drop tubes (flexible section) & NA & NA & 7 & 7 \\
\hline 6.1.3 Tube interface frames & NA & NA & 40 & 40 \\
\hline 6.2 Internal bulkhead & NA & NA & 442 & 593 \\
\hline 6.2.1 Panel & NA & NA & 386 & 529 \\
\hline 6.2.2 Interface frame & NA & NA & 56 & 64 \\
\hline Subtotal & $\mathbf{4 0 8 5}$ & $\mathbf{5 5 3 0}$ & $\mathbf{2 2 7 1}$ & $\mathbf{3 0 3 2}$ \\
\hline 7.0 Structural non-optimum & 1021 & 1383 & 568 & 758 \\
\hline Total Structure & $\mathbf{5 1 0 6}$ & $\mathbf{6 9 1 3}$ & $\mathbf{2 8 3 9}$ & $\mathbf{3 7 9 0}$ \\
\hline
\end{tabular}

Table 12. Itemized WBS Statements for the Monolithic Concepts. 
Shown in Table 13 are the specific volumes, surface areas and floor areas for the various Monolithic concepts studied.

\begin{tabular}{|l|c|c|c|c|}
\hline \multicolumn{1}{|c|}{$\begin{array}{c}\text { Parameter, } \\
\text { units }\end{array}$} & A & B & C & D \\
\hline $\begin{array}{l}\text { Dimensions, } \\
\text { meters }\end{array}$ & $\begin{array}{c}\text { 7.5 Diameter } \mathrm{x} \\
7.6 \text { Height }\end{array}$ & $\begin{array}{l}\text { 7.5 Diameter } \\
\text { x 10.4 Height }\end{array}$ & $\begin{array}{c}\text { 7.5 Diameter } \mathrm{x} \\
3.4 \text { Height }\end{array}$ & $\begin{array}{c}7.5 \text { Diameter } \mathrm{x} \\
4.5 \text { Height }\end{array}$ \\
\hline Volume, $\mathrm{m}^{3}$ & 230 & 327 & 102 & 146 \\
\hline Surface area, $\mathrm{m}^{2}$ & 198 & 295 & 118 & 142 \\
\hline Floor area, $\mathrm{m}^{2}$ & 120 & 163 & 33.5 & 41.2 \\
\hline
\end{tabular}

Table 13. Monolithic Habitats Definition Summary (per module).

\section{Option 4 - Mobile Habitats}

In Option 4, the Habitats remain on the Lander, the Lander is mobile, and at outpost complete, there are three Habitat units as shown in Figure 9. The Habitat units are landed on the lunar surface as pre-integrated units that are moved by the Lander and connected together using the Lander mobility system. All subsystems and utilities are pre-integrated into each of the Habitat units. The first PLM that lands is also on a mobile Lander and is reused and retro fitted for exercise and medical operations and becomes the third unit. The Habitats remain on the mobile Landers, so they have the capability to disconnect and move the outpost to a new location. A horizontal cylinder geometry was selected for the Option 4 Habitat units.
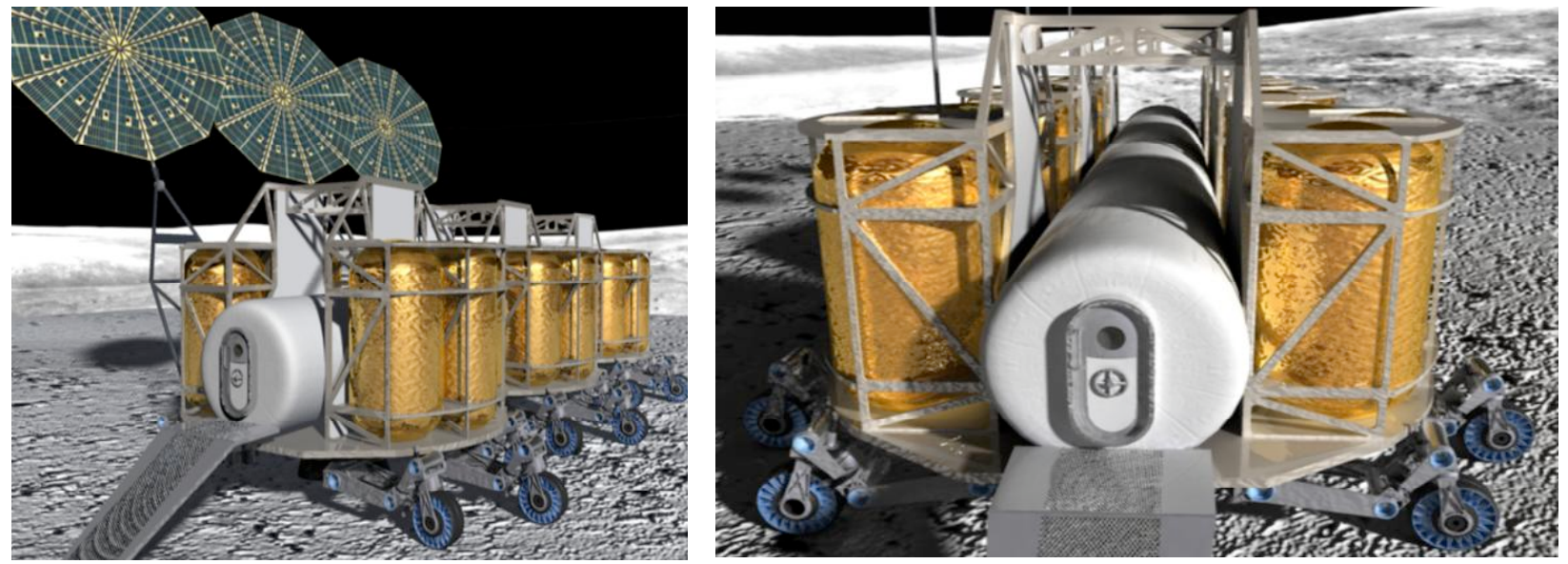

Figure 9. Mobile Habitats in outpost configuration.

Since the Option 4 Habitats remain on the Lander, no external cargo truss was required, and the diameter of the shell was expanded to 3.0 meters. Given that diameter, and a dome aspect ratio $(\alpha)$ of $0.47(0.71 \mathrm{~m} / 1.5 \mathrm{~m})$, the Habitat could have a total length of 8.5 meters and still fit within the dynamic envelope of a 10-meter diameter launch vehicle payload shroud of 8.8 meters. The total volume of an Option 4 mobile Habitat is approximately $55 \mathrm{~m}^{3}$. In this study, three versions of the Option 4 Habitats were sized; the original 8.0 meter long, the 8.5 meter long that was baselined in the architecture, and a 4.0 meter-long version that was considered as a sortie 
Habitat. Based on the results from the Mini-Hab sizing (lightest mass, and minimum gage structure), the pressure shell and floor structures were assumed to be aluminum-lithium sandwich structure. The mass results for the three Habitats sized are summarized in Table 14.

\begin{tabular}{|c|c|c|c|}
\hline \multirow{2}{*}{ Structural Item } & \multicolumn{3}{|c|}{ Mass, $\mathbf{~ g}$} \\
\cline { 2 - 4 } & $\mathbf{8 . 5} \mathbf{~ m ~ L}$ & $\mathbf{8 . 0} \mathbf{~ m ~ L}$ & $\mathbf{4 . 0} \mathbf{~ m ~ L}$ \\
\hline 1.0 Pressure shell & 453 & 431 & 252 \\
\hline 1.1 Forward dome & 38 & 38 & 38 \\
\hline 1.2 Fwd. dome-to-barrel frame & 30 & 30 & 30 \\
\hline 1.3 Barrel & 317 & 295 & 116 \\
\hline 1.3.1 Hard shell & 317 & 295 & 116 \\
\hline 1.3.2 Expandable & NA & NA & NA \\
\hline 1.4 Barrel-to-aft dome frame & 30 & 30 & 30 \\
\hline 1.5 Aft dome & 38 & 38 & 38 \\
\hline 2.0 Legs/ground support system & NA & NA & NA \\
\hline 3.0 Launch/Lander integration & 102 & 102 & 33 \\
\hline 4.0 Floor system & 122 & 116 & 57 \\
\hline 4.1 Floor beams & 20 & 19 & 9 \\
\hline 4.2 Floor panels & 82 & 78 & 39 \\
\hline 4.3 Edge supports & 20 & 19 & 9 \\
\hline 5.0 Secondary structure support & 212 & 200 & 107 \\
\hline 6.0 External cargo truss & NA & NA & NA \\
\hline Subtotal & $\mathbf{8 8 9}$ & $\mathbf{8 4 9}$ & $\mathbf{4 4 9}$ \\
\hline 7.0 Structural non-optimum & 222 & 212 & 112 \\
\hline Total Structure & $\mathbf{1 , 1 1 1}$ & $\mathbf{1 , 0 6 1}$ & $\mathbf{5 6 1}$ \\
\hline
\end{tabular}

Table 14. Mobile Habitat Structural Mass Summary.

For launch/Lander integration for the 8.5 and 8.0 meter long Habitats, a gross mass of $5075 \mathrm{~kg}$ was assumed, and for the 4.0 meter long unit, a gross mass of $1652 \mathrm{~kg}$ was assumed. The majority of mass differences between the three units are in the pressure shell barrel and the floor system, both of which are highly dependent on module length. However, it is noted that the structural mass per unit length varies only by approximately 6 percent for the three units. Although the modules are slightly larger in diameter than the Mini-Habs, the floor height and width are identical. Major features of the structural definition are summarized in Table 15.

\begin{tabular}{|l|c|c|c|}
\hline \multicolumn{1}{|c|}{ Parameter, units } & Hard-shell, 8.5 meter & Hard-shell, 8.0 meter & Hard-shell, 4.0 meter \\
\hline $\begin{array}{l}\text { Dimensions } \\
\text { (expanded), meters }\end{array}$ & $\begin{array}{c}\text { 3.0 Diameter } \mathrm{x} \\
8.5 \text { Long }\end{array}$ & $\begin{array}{c}\text { 3.0 Diameter } \mathrm{x} \\
8.0 \mathrm{Long}\end{array}$ & $\begin{array}{c}\text { 3.0 Diameter } \mathrm{x} \\
4.0 \text { Long }\end{array}$ \\
\hline Volume, $\mathrm{m}^{3}$ & 55.0 & 50.0 & 25.0 \\
\hline Floor area, $\mathrm{m}^{2}$ & 15.1 & 14.2 & 7.1 \\
\hline Floor height, meters & 0.33 & 0.33 & 0.33 \\
\hline Floor width, meters & 1.78 & 1.78 & 1.78 \\
\hline
\end{tabular}

Table 15. Option 4 Mobile Habitat Definition Summary (per module). 


\section{Option Comparisons}

At Outpost Complete, the number of Habitat modules varied depending on the architecture option. Option 2 consisted of either 5 hard shell units or 3 hybrid (mid-expandable) units, all outpost versions of Option 3 consisted of one unit, and the Option 4 mobile Lander outpost consisted of 3 units. Since there is no total or habitable volume requirement for the outpost, those quantities for each option vary substantially, making it difficult to compare and infer any sort of objective conclusions about each option's viability as a Habitat, especially from a human-factors standpoint. However, a series of normalizations were calculated for the structural mass of each option (see Table 16), allowing for relative comparisons of the various structural implementations.

\begin{tabular}{|c|c|c|c|c|c|c|c|}
\hline \multirow[t]{2}{*}{ Option } & \multicolumn{2}{|c|}{ Mass, kg } & \multirow{2}{*}{$\begin{array}{c}\text { Mass/ } \\
\text { volume, } \\
\text { kg/m }{ }^{3}\end{array}$} & \multicolumn{2}{|c|}{ Mass/area, kg/m ${ }^{2}$} & \multicolumn{2}{|c|}{$\%$ of total mass } \\
\hline & Unit & Outpost & & $\begin{array}{l}\text { Shell } \\
\text { Area }\end{array}$ & $\begin{array}{l}\text { Floor } \\
\text { Area } \\
\end{array}$ & Shell & Floor \\
\hline \multicolumn{8}{|l|}{ Opt. 2 Mini. } \\
\hline $\mathrm{Al}-\mathrm{Li}-5.0 \mathrm{~m}$ & 805 & 4025 & 29.3 & 17.3 & 90.4 & 32.7 & 8.9 \\
\hline $\mathrm{Al}-\mathrm{Li}-6.0 \mathrm{~m}$ & 908 & 4540 & 27.3 & 16.5 & 84.9 & 33.6 & 9.5 \\
\hline PMC - Baseline & 916 & 4580 & 33.3 & 19.7 & 102.9 & 36.9 & 9.4 \\
\hline $\begin{array}{l}\text { PMC - } \\
\text { Reduced gage }\end{array}$ & 845 & 4225 & 30.7 & 18.2 & 94.9 & 35.3 & 8.2 \\
\hline Al-Li Hybrid & 933 & 2799 & 14.8 & 10.5 & 52.4 & 29.6 & 19.4 \\
\hline PMC Hybrid & 1050 & 3150 & 16.7 & 11.8 & 59.0 & 32.0 & 20.5 \\
\hline \multicolumn{8}{|l|}{ Opt. 3 Mono. } \\
\hline A & 5106 & 5106 & 22.2 & 25.8 & 42.6 & 24.8 & 35.2 \\
\hline $\mathrm{B}$ & 6913 & 6913 & 21.1 & 23.4 & 42.4 & 24.8 & 32.5 \\
\hline $\mathrm{C}$ & 2839 & 2839 & 27.8 & 24.1 & 84.7 & 26.6 & 12.2 \\
\hline $\mathrm{D}$ & 3790 & 3790 & 26.0 & 26.7 & 92.0 & 25.5 & 16.3 \\
\hline \multicolumn{8}{|l|}{ Opt. 4 Mobile } \\
\hline Al-Li-8.5m & 1111 & 3333 & 20.2 & 12.9 & 73.6 & 40.8 & 11.0 \\
\hline Al-Li-8.0m & 1061 & 3183 & 21.2 & 13.1 & 74.7 & 40.6 & 10.9 \\
\hline $\mathrm{Al}-\mathrm{Li}-4.0 \mathrm{~m}$ & 561 & NA & 22.4 & 12.9 & 79.0 & 44.9 & 10.2 \\
\hline
\end{tabular}

Table 16. Comparison of Habitat Structural Masses and Efficiencies.

The total outpost Habitat structural mass varies significantly for the various options studied. The structural mass per unit volume should be considered a primary figure of merit for comparing the Habitat structures. Based on this, the hybrid expandables are the most structurally efficient concept, with efficient hardshell concepts (option 4, Monolithics A and B) being approximately $33-47$ percent heavier. The Mini-Habs are approximately twice as heavy because common structure (domes and frames) and structure based on Habitat total gross mass are more dominant for the smaller volume. Comparing the shell mass per unit area of the option 4 and option 2 Habs also shows this trend. The trends within the option 2 and 4 Habitats also show that structural efficiency is improved for horizontal cylinder configurations as the Habitat length and diameter increases. Reducing the PMC minimum gage from ten to eight plies per facesheet results in an 
approximately 10 percent reduction in the unit mass, making it essentially equivalent to the Al-Li mass.

Since the Habitats are outfitted and used in a gravity field, the floor area also should be considered an important figure of merit. In this regard, the early monolithic concepts (A and B) are the most efficient in terms of the structural mass per unit floor area. The hybrid expandable concept is also very efficient; approximately 25 percent heavier than the early monoliths while the longer and wider option 4 Habitats are approximately 75 percent heavier. Interestingly, the later monolithic concepts are twice as heavy as the early concepts, equivalent to the Mini-Habs. The shell mass ranges from $25-45$ percent of the total structure, demonstrating the large impact other structural items have on the mass. Since many of those items were estimated parametrically or with allocations, it is important to add fidelity to these items. However, accomplishing that requires a great deal more design definition, knowledge of loads, environments, and integration with other systems than is typically available in an architecture study. Although the floor mass is a larger percentage of the total structure mass for the hybrids and early monolithic concepts, this is because they have much more floor area. This insight provides guidance for where to focus efforts on trying to reduce mass for these concepts.

\section{Concluding Remarks}

A series of lunar surface Habitat structural concept definitions and associated sizing and mass estimates were developed for the Lunar Architecture Team Phase 2 study. The structures subsystems team developed a generic set of itemized structural items representing primary Habitat structure and analytical methods for sizing and estimating the mass of each element. The analytical methods vary from simple mass allocations to engineering-based equations, are different for each element, and are summarized in this paper. This process increased insight into Habitat structural sizing by allowing the mass contribution of individual elements to be assessed and compared while also allowing the analysis method fidelity for each element to vary according to knowledge of loads, materials and concept definition of the element. The approach will also allow low fidelity methods to be replaced by higher fidelity methods on an individual element basis as design knowledge increases and concept definition matures. More refined Habitat structural design and more accurate mass estimates depend on increasing the knowledge in areas such as; loads and load cases over the lifetime of the Habitat, the impact of lunar environments on material end-of-life properties, material property values at lunar surface (hot and cold) temperatures, and the threat environment and damage tolerance requirements, and incorporating that knowledge into the design process.

The mass estimating process has the ability to capture trends resulting from changes in major design parameters, such as geometry, dimensions, material type, internal pressure load and factors-of-safety. For example, both metallic and PMC materials were assessed for the option 2 Mini-Hab application. The resulting minimum gage shell sizing for each material indicated that the metallic structure would be lighter, and identified key areas for future investigations and detailed definition. Although the minimum gage values used in this study represent values for damage tolerant primary structure on commercial transports, it is not known if these values are correct for a lunar Habitat; the threat environments are very different. Thus, the study results indicate that it is very important to establish the minimum gage values for primary structure 
considering the full suite of lunar environments (especially temperature, radiation degradation and tolerance to damage caused by micro-meteoroid and Lander ejecta impact) as well as the design lifetime for the structure.

The study method also allowed hard-shell sections of Habitat barrel structure to be replaced by soft-shell (expandable) sections in the hybrid Mini-Hab concepts. The resulting hybrid structure was the most structurally efficient of all concepts evaluated. However, the application of expandable structures on the lunar surface is at a low readiness level and technology development is needed to substantiate the use of this concept. In particular, the material durability (property retention) under long term environmental exposure to lunar surface environments must be established. Of particular concern is the long-term creep behavior of soft good materials for Habitat lifetimes that could exceed 15 or 20 years. Structurally efficient methods for deploying expandable items such as floors, utilities and doors/hatches will also be required and must be developed and validated.

The habitability of the outpost will be very important for long term human stays on the lunar surface. From a human factors standpoint, the "goodness" of a particular Habitat might be measured by parameters such as the total volume or floor area. Although requirements have yet to be established for either parameter, the results from this study show that structural efficiency varies substantially across the different Habitats studied for each. Hybrid concepts proved to be the most structurally efficient on a mass-per-unit-volume basis, with the best hardshell concepts at least 33 percent heavier. For hardshell concepts, efficiency is improved by having larger (longer and larger diameter) Habitats, although efficiency was shown to be degraded by choosing inefficient shapes. The process reported here allowed insight into why the smaller Habitats (option 2 Mini-Habs) were least efficient. The two major reasons are that common structure (domes and frames for example) as well as structure based on the Habitat gross mass are both more dominant in the smaller Habitats. In terms of floor area, the results show that multi-story Habitats (Monolithics A and B) have much higher mass efficiency than the single floor options, no matter what the size of the Habitat. For single story/floor concepts, the hybrid is most efficient.

Designing a Habitat system for the lunar surface will be a complex endeavor, with many trades made between the major Habitat subsystems as well as the Habitat and the other systems in the architecture (Lander for example). The results of this study show that many different solutions are possible within the structural subsystem, with a wide range of Habitat sizes, masses and structural efficiencies possible. In order for Habitat structural design to progress, a wide set of requirements (such as total volume, floor area, threat environments and damage tolerance) must be established. Characterizing the lunar environments and their impact on the long term durability of potential structural materials is also imperative to gain confidence in designs and mass estimates. Due to the lunar architecture being in an early concept definition phase, with firm requirements possibly not established for some time, it is important to maintain and study a variety of options for the Habitat structure. Because of their potential for optimum mass and volume efficiency, hybrid and pure expandable Habitat structures should continue to be developed. 


\section{References}

Agarawal, B. L.; Sobel, L. H.: Weight Comparisons of Optimized Stiffened, Unstiffened and Sandwich Cylindrical Shells. AIAA Journal of Aircraft, Volume 14, Number 10, October 1977, pages $1000-$ 1008.

Anon., Buckling of Thin-Walled Doubly Curved Shells, NASA SP-8032, August 1969.

Heineman, Willie, Jr; DESIGN MASS PROPERTIES II - Mass Estimating And Forecasting For Aerospace Vehicles Based On Historical Data. Systems Definition Branch Technology and Project Implementation Office Engineering Directorate, JSC- 26098, November 1994.

Heineman, Willie, Jr; Design Mass Properties - Guidelines and Formats for Aerospace Vehicles. Advanced Programs Office Systems Definition Branch, JSC- 23303, March 1989.

High Speed Research Program, HSR Design Requirements, Objectives and Compliance Document, May 17, 1996. The Boeing Company, Contract NAS1-20220.

High Speed Research Program, HSCT Materials Property Database, Revision D, June 30, 1998. The Boeing Company, Contract NAS1-20220.

Mechanics of Materials, Beer and Johnson, McGraw-Hill, 1981.

Mikulas, Martin M.; Bush, Harold G.; and Card, Michael F.: Structural Stiffness, Strength and Dynamic Characteristics of Large Tetrahedral Space Truss Structures. NASA TM X-74001, March 1977.

Niu, Michael C. Y.: Composite Airframe Structures - Practical Design Information and Data. Conmilit Press Ltd. Hong Kong, 1992.

Ring, L.R.: Process Development and Fabrication of Space Station Type Aluminum-Clad Graphite Epoxy Struts. NASA CR-181873, 1990.

Shell Analysis Manual, Baker, et al., NASA CR-912, April 1968.

Shiedeler, John L.; Anderson, Melvin S.; and Jackson, Robert L.: Optimum Mass- Strength Analysis For Orthotropic Ring-Stiffened Cylinders Under Axial Compression. NASA TN D-6772, July 1972.

Stein J., Cadogan D., Fredrickson T., Sharpe G.; Deployable Lunar Habitat Design and Materials Study, Phase I Results, Report number 711855, ILC Dover Inc., January 1997.

Theory of Plates and Shells, Timoshenko and Woinowsky-Krieger, McGraw-Hill, 1987.

The Behavior of Sandwich Structures of Isotropic and Composite Materials, Vinson, Technomic Publishing, 1999.

Thurston, G.A.; and Holston, A.A. Jr.; Buckling of Cylindrical Shell End Closures by Internal Pressure. NASA CR-540, July 1966. 